\title{
Accelerated Discovery of the Polymer Matrix for Cartilage Repair Through Machine Learning Algorithms
}

\section{A. Mairpady}

UAE University: United Arab Emirates University https://orcid.org/0000-0002-9827-3722

Abdel-Hamid I. Mourad

UAE University: United Arab Emirates University https://orcid.org/0000-0002-8356-0542

A S Mohammad Sayem Mozumder ( $\sim$ a.s.mozumder@uaeu.ac.ae )

UAE University: United Arab Emirates University https://orcid.org/0000-0001-5613-0929

Research article

Keywords: material informatics, random forest regression, multinomial logistic regression, articular cartilages.

Posted Date: June 4th, 2021

DOI: https://doi.org/10.21203/rs.3.rs-572145/v1

License: (c) (i) This work is licensed under a Creative Commons Attribution 4.0 International License. Read Full License 


\section{Abstract}

Cartilage repair is one of the most challenging tasks for the orthopedic surgeons and researchers. The primary challenge lies on the fact that the development of the extracellular matrixes requires specialized cells known as chondrocytes which are sparse in numbers. Chondrocytes' minimal self-renewal capacity makes it further troublesome and expensive to repair the cartilages. In designing successful substitutes for the cartilages, the selection of materials used for the scaffold fabrication plays the central role among several other important factors in order to ensure the success of the survival and proliferation of any biomaterial substitutes. Since last few decades, polymer and polymers' combination have been extensively used to fabricate such scaffolds and have shown promising results in terms of mechanical integrity and biocompatibility. In an empirical approach, the selection of the most appropriate polymer(s) for cartilage repair is an expensive and time-consuming affair, as traditionally, it requires numerous trials. Moreover, it is humanly impossible to go through the huge library of literature available on the potential polymer(s) and to correlate their physical, mechanical and biological properties that might be suitable for cartilage tissue engineering. With the advancement of machine learning, material design may experience a significant reduction in experimental time and cost. The objective of this study is to implement an inverse design approach to select the best polymer(s) or composites for cartilage repair by using the machine learning algorithms, such as random forest regression (i.e., regression trees) and the multinomial logistic regression. In these algorithms, the mechanical properties of the polymers, which are similar to the cartilages, are considered as the input and the polymer(s)/composites are the predicted output. According to the random forest regression and multinomial logistic regression, the polymer(s)/composites (i.e., the output) having the closest characteristics of the articular cartilages were found to be a composite of polycaprolactone and poly(bisphenol A carbonate) and a blend of polyethylene/polyethylene-graft-poly(maleic anhydride), respectively. These composites exhibit similar biomechanical properties of the natural cartilages and initiate only minimal immune responses in the body environment.

\section{Introduction}

Cartilages are the connective tissues mostly present in the long bones in the human body. Its primary function is to provide lubrication and to act as a cushion against the friction on movement. The damage to these tissues can be occurred due to trauma, obesity, aging, osteoarthritis, and by few other diseases. Often even a minute tear in the cartilage over time leads to the further irreversible damage[1,2]. Patients with disintegration of cartilages experience debilitating joint pain followed by restricted movement[3, 4]. Alarmingly, more than 200 million people are suffering from the osteoarthritis daily around the globe[5].

Chondrocytes play the significant role by producing the extracellular matrix (ECM) sought for the repair of cartilages. However, the chondrocytes have only limited capacity of self-renewal, this makes the cartilage repair difficult[6, 7]. Therefore, the insertion of cartilage substitutes is deemed to be the potential solution. The damaged cartilages are often replaced by using several surgical procedures such as the total knee replacement, microfracture, and mosaicplasty. Moreover, as a possible therapeutic option, the 
chondrocytes extracted from the donors are transplanted to the damaged area to reduce the severity of the disease [8]. However, the rejection of the implanted chondrocytes by the recipient(s) makes this procedure unpredictable, while finding a right donor is also troublesome. Especially in the case of chondrocytes, instability of the monolayer is a crucial obstacle $[9,10]$. Therefore, it is evident that none of these techniques offers long lasting solution to the cartilage damage related diseases[11-13] .

Recently, tissue engineering has delivered promising results in the field of cartilage regeneration and repair. The 3D scaffolds play a crucial role in replacing biological tissues through developing fully functioning load-bearing biomaterials. Fabricated 3D scaffolds should have the capacity to considerably mimic the characteristics and functions of the extracellular matrix (ECM) of the cartilages[14-16]. Saying that, the 3D scaffolds should acquire mechanical integrity and appropriate cell attachment, cell adhesion, and cell proliferation. Over the years, the polymers have shown tremendous potential to be molded as the $3 D$ scaffolds having above mentioned properties[17-20]. Using many different combinations of natural and synthetic polymers, many have attempted to develop fully functioning and weight-bearing cartilages. However, the complexity of natural cartilages makes it very challenging for the designed biological substitutes. As a whole, the advanced biomaterials typically fall short either in biomechanics or in functioning[21, 22].

Moreover, the discovery of novel combinatory materials for cartilage tissue engineering typically takes long time (i.e., 10-20 years) from the material design to the commercialization. Particularly, the material design procedure is one of the most tedious, time-consuming, and costly affairs in this regard[23, 24]. Due to going through such a lengthy procedure of material design and development, most of the time, either the developed product turns to be outdated, or by then the initial hypothesis of the researchers would become irrelevant or inadequate due to the advancement of research in the respective field. Moreover, during the period of evolution of designing a commercial product, an immense amount of data is being generated in the relevant field(s). Manually, it becomes laborious and time-consuming to find and interpret the data patterns or to extract any meaningful information out of it. With the advancements in information technology, information can be retrieved from these data to implement knowledge discovery by data mining through machine learning algorithms $[25,26]$. The process and tools of data mining provide immense help in executing the algorithms needed for material informatics[27, 28]. In material informatics, a vast amount of data in the form of experimental outcomes from the previous research is being retrieved, and using the tools of machine learning, facilitation of knowledge discovery is implemented [26]. Indeed, the fourth dimension of material science involves extracting information from the literatures with the aid of the machine learning algorithms. In this way, the knowledge can be retrieved by discovering the association between the data, pattern recognition and clustering without any human intervention. This approach leads to speedy design and development of novel materials as once the information is attained, a minimal amount of trial and error is needed to be carried out[29, 30].

Consequently, the use of material informatics in developing new materials from the potential polymer(s) is currently in great demand. More precisely, in recent years, the implementation of material informatics and machine learning in materials science (i.e., polymer design, feature selection) has increased 
exponentially[28, 29]. In material science, experimental design can be carried out through direct design and inverse design approach. Direct or conventional design approach involves with the prediction of the properties of the fabricated materials by taking 'materials' as the input. Recently, with advancement of machine learning a new technique of material design, namely inverse design, can be implemented. In inverse design is a fully data driven approach that predicts the target materials by putting the relevant material properties (i.e., molecular structures, physical, mechanical, thermal, biological etc.) as the input[31, 32].

For example, Venkatraman et al. (2018) used an evolutionary algorithm to virtual screening of several classes of monomers while developing a batch of polymeric materials with high refractive index to determine which chemical groups have major effect in increasing the refractive indices of the developed materials[33]. In another study, Le (2020) used Gaussian Process Regression method to predict the tensile strength of the nanocomposites by setting the types and mechanical properties of the polymer matrices, types and properties of carbon nanotubes as nanofillers and incorporation parameters as inputs[34]. While Venkatraman et al. (2018) [33] and Le (2020) [34] adopted direct design approach, in a recent study, Kim et al.[31] developed deep learning neural network inverse design model to predict high performance organic molecules by creating a relationship between the structure and their material properties. Very recently in 2020, Kim et al.[35] employed the inverse design approach through neural network algorithm in which 31,713 known zeolites properties were considered as input to predict 121 porous nanostructures.

To the best of the authors' knowledge, no study has yet been conducted to predict the polymer(s) or polymer composites to mimic human cartilages by machine learning algorithm(s). The primary objective of this study is to implement an inverse design approach to obtain the target polymer(s)/composites that exhibit similar properties of the human cartilage. This research was carried out in four steps, initially, the systematic bibliometric analysis was carried out using the review articles' citation data in the field of cartilage tissue engineering, and then the relevant database was created using PoLyInfo library. Then machine learning techniques ( i.e., random forest regression and multinomial logistic regression) were used to run both single and multiple properties optimization. In the final step the machine learning algorithms was employed to predict the polymer(s) or polymer composites that possess similar functional properties of the human cartilages (e.g., tensile modulus, tensile strength, and elongation at break).

\section{Methodology}

\section{Bibliometric analysis:}

Bibliometric analysis is a powerful tool to allow the researchers to get an overview and/or the trend in which the specific research field is heading into. The benefit of this analysis is extract the original articles and their citation summary to run the overall publication analysis in a particular field of interest $[36,37]$. From the large group of polymers and subgroups of polymers available in the market, the objective of this 
study was to discover the polymers/composites which are among the best to be used in cartilage repair. To retrieve the major groups of polymers/composites, the bibliometric analysis was carried out. In this study, the using 'cartilage' as the keyword, review journal articles' title, abstract and their citation reports were extracted, and bibliometric analysis was run in R program. The results containing the top ten highly cited articles were tabulated and summarized in table 1. Each review paper linked to cartilage repair was manually reviewed, and the names of the major polymers/composites mentioned in these papers were extracted and listed. The selection of these polymers/composites was done based on their recurrent usage in cartilage tissue engineering. The final selection of the polymers/composites was made based on the availability of data in the Polyinfo database summarized in table 2.

\section{Database creation:}

For the success and durability of the biomaterials, mechanical properties play a substantial part[38, 39]. Specifically, in cartilages, a primary symptom of the disease (i.e., osteoarthritis) is the deterioration of the mechanical properties of the cartilages[40]. Concerning the biomechanical properties of the cartilages, the tensile strength, tensile modulus, and elongation at break are the most sought mechanical properties, since the main function of cartilage is to hold/resist the amount of stress and compressive force exerted on the body part(s) of interest at any given moment[41],[42, 43]. The key mechanical properties of the native articular cartilages were extracted from the literature and summarized in table 3 . The tensile strength, tensile modulus and elongation of the natural cartilages reported in table 3 are $35 \mathrm{MPa}, 3-100$ $\mathrm{MPa}$ and $2-140 \%$, respectively ${ }^{59}$. However, under $15 \%$ less strain, the tensile modulus reaches only up to 5 to $10 \mathrm{MPa}$ [44]. Therefore, the database of the polymers/composites has been created taking into account of these key mechanical properties of the natural cartilages.

PolyInfo is a section of the NIIMS materials database, which extracts numerical data from the relevant sources (i.e., academic articles)[47]. In this study, the numerical values of the major mechanical properties of the polymers/composites used in cartilage repair have been retrieved using the Polylnfo database. The summarized database (table 2) includes a collection of ninety-seven

polymers/composites and their related mechanical properties. The ranges of the extracted values for each of the mechanical properties were chosen as the input or independent variable in this study, whereas the names of the polymers/composites were taken as the output or the dependent variable (i.e., categorical in nature) for the machine learning algorithms. The input and output variables were chosen in such a way to implement the inverse design approach (Fig. 1). Through this design approach, the polymers/composites' names were predicted by using properties of the natural cartilage extracted from journal articles (summarized in table 3).

\section{Machine learning Algorithms}

\section{The Random Forest Regression:}

Random forest regression is an evolutionary machine learning technique that can handle the supervised and unsupervised learning, a continuous variable, and the categorical variable. Its principal function is to 
drive an accurate functional relationship between the independent variables and the dependent variable[48]. This technique involves an ensemble learning method wherein the rules are developed by splitting the data into smaller quantities leading to developing the smaller decision trees against the predictor. The concept of the decision tree was initially introduced by Breiman et al. in 1984[49]. In this method, decisions are not derived from using a single tree but from the cluster of trees. This diversion of data to these trees usually enables the model to be more stable[50]. On modeling, the result can be developed using 100 trees or 10,000 trees, and each tree actualizes into its regression function. The final decision is a collective output of all regression equations[51].

Variance in the decision tree can be minimized by using the bootstrapping or bagging approach. In the process of bootstrapping, the sample is randomly subdivided from the training set to retrieve a bunch of decision trees, and this is continued with the new sample replacement using CART algorithm[52]. On completion, the aggregated and averaged results are obtained using the following mathematical equation to secure the final output:

$$
Y^{n}=\frac{1}{N} \sum_{i=1}^{N} Y_{i}^{n}
$$

Here, $Y^{n}$ is the final predicted output and $Y^{i}$ is the aggregated and averaged output of the generated trees, $\mathrm{N}$ is the number of decision trees[53].

In this study, the simulations (i.e., training and testing) were run in R version 3.6.1[54], and the package randomForest[55] was implemented to retrieve the decision trees. The predictor (i.e., output) chosen was a nominal categorical variable. Once the predictor was assigned to be the categorical variable $k$ (nonnumeric variable), the random forest regression automatically assigns the value to be $k-1$ [56]. Adequacy of the modeled data to predict an output was demonstrated using the out of bag (OOB) error. In the random forest regression, a large number of trees were developed, and the aggregated average of predicted trees were drawn. The difference between the predicted and observed data was noted as the out-of-bag error for each observation[57].

In this study, the random forest regression operation was performed according to the flowchart shown in Fig. 2. For the success of any machine learning algorithm, the preprocessing of the data is a crucial step. The main purpose of preprocessing is to convert raw data into the structured ones, through which errors are minimized. The raw data is first inserted into $\mathrm{R}$ program, and then the preprocessing steps include assignment of the right variable(s) into factor or numeric, recalibration of the missing value(s) and removal of the outliers. Then the data was being split into the training and testing sets. To assure the accuracy and to minimize the overfitting of data, bagging/bootstrapping is done in the algorithm. These steps were carried out systematically, as mentioned in Fig. 3, to input the operational data into a random forest regression algorithm. Upon bootstrapping, resampling of the observed and training data set was done followed by the formation of multiple trees from the subset of data. In the random forest regression algorithm, the averaging and aggregating of each tree has been done. In this model, the goodness of fit 
was checked with the mean square error to determine whether the error is stabilized or not. On achieving the error to the minimum, the testing data (i.e., properties of the polymeric composites) without the output was being fed into the model. Once the difference between the predicted and the observed values was found to be the minimum, the mechanical properties of natural cartilages (shown in table 3 ) was inserted into the system to obtain the desired output (i.e., the name of the polymers/composites).

\section{Multinomial logistic regression:}

For dealing with the categorical dependent variable with multiple levels, very few modelling techniques are available. Among those few techniques, multinomial logistic regression (MNLR) is one of the most suitable machine learning algorithms to model the data having multiple factors and levels. The data set used to implement the multinomial logistic regression technique is typically categorical, and has multiple levels. This approach can deduce the probability of occurrence of the output in the dataset. This regression is distinct from its linear regression as it implements a sigmoidal behavior to its data[58]. To evaluate the modeled data having a categorical response variable, it is crucial to develop a relationship between the logarithm odds and the explanatory variables for the modeled data. It is given by the following equation:

$$
\log \left(\frac{p}{1-p}\right)=\beta_{0}+\beta_{1} x_{1}+\cdots+\beta_{i} x_{i}
$$

where $x$ is the explanatory variable, $\beta$ s are the regression coefficient of the factor(s), and $p$ is the predicted probability. In dealing with the multiclass regression problem, a relationship between the input and output is developed by the following equation:

$$
\mathrm{P}(y=k / x)=\frac{\exp ^{\left(\beta_{0}^{k}+\beta_{1}^{k} x_{1}+\ldots \ldots \ldots+\beta_{i}^{k} x_{i}\right)}}{\sum_{J=1}^{K} \exp ^{\left(\beta_{0}^{k}+\beta_{1}^{k} x_{1}+\ldots \ldots \ldots+\beta_{i}^{k} x_{i}\right)}}
$$

where, $k$ is the number of classes and $\beta$ s are the regression coefficient of the factor(s)[59].

The overall workflow of MNLR is depicted in the form of a flowchart in Fig.4. Initial step includes the preprocessing of the data, as the computer cannot differentiate between the factorial and numerical variables. Therefore, each parameter was needed to be assigned as either numerical or categorical. Final step of the data preprocessing includes the removal of any outlier(s) from the dataset. To check the accuracy of the prediction, the data was divided into training and testing sets. Then the training set was being fed into the algorithm and the likelihood ratio test was performed. The deviance of the null hypothesis and the residual was noted. Model's goodness of fit was confirmed. Using the testing data without the output new prediction was retrieved. Once the difference of the observed and the predicted values (i.e., residual) was minimum, then the prediction was done using the tensile modulus, tensile strength and the elongation at break of the natural cartilages. 


\section{Results And Discussion}

\section{Bibliometric analysis}

The most convenient and least time-consuming approach to obtain an overall standing (i.e., trend, current progress etc.) of the any research field is the bibliometric analysis. It enables the researchers to summarize the overall research trends and to develop the link between the variables in the field(s). The bibliometric analysis can be used to analyze the most evaluated component(s) in the area of the research[60,61]. Particularly in tissue engineering, huge number of materials/composites are being investigated to evaluate their efficacy to replace damaged or degrading cartilages. Among them, polymers are in the frontline in creating biomaterial substitutes (i.e., scaffolds)[62-64]. In cartilage tissue engineering, several different types and combinations of polymers are being investigated to mimic articular cartilages $[8,65]$. To select the most suitable polymer(s) and/or the combination of polymers the bibliometric analysis was used in this study. The review papers were extracted from the Web of Science using the 'cartilages' and 'polymers' as the keywords. The review articles' citation details were downloaded for the period of 2005-2020. Using bibliometrix package in R program[66], a list of highly cited review papers where extracted and the top ten cited papers are being summarized in Table 1.

Upon running the bibliometric analysis using 'cartilages' and 'polymers' as keywords, the most recurrent words were displayed in the form of the wordcloud as shown in Fig. 1. All of the keywords shown in the wordcloud appeared more than 70 times in the published literatures. In Fig. 5, the keywords are displayed in larger to smaller fonts depending on their recurrence in the literature. It is evident from Fig. 5 that cartilage, scaffolds properties, collagen, polymers, hydrogels, mechanical strengths and chondrocytes are found to be among the most recurrent keywords. In other words, these are the most important parameters to consider while designing a new material for cartilages repair. In this study, our focus was limited to the mechanical strength of the polymer(s) to mimic the articular cartilages. Considering the mechanical properties (i.e., tensile strength, tensile modulus and elongation etc.), based on the recurrent mentions in the review papers and the data availability in the PoLyInfo database, the list of polymers/composites have been prepared to be used in the machine learning algorithms (shown in Table 2).

\section{Selection and preprocessing of the database}

Depending on the load or the direction of stretching, the components of cartilages, especially the collagen fibrils and proteoglycans, move towards the direction of the load. Initially, when the tensile stress is less, only the collagen fibers' realignment occurs[67]. Once the cartilage experience large deformation, the collagen attains large amount of tensile stiffness due to the stretching of collagen fibers. Once the tension is removed the collagen fibrils and proteoglycans move back to their normal position. Indeed, the viscoelasticity of cartilages in tension is best described by the mechanical properties, such as, tensile strength, elongation at break and tensile modulus $[43,67,68]$. Therefore, in this study the ranges of the tensile strength, elongation at break and tensile modulus have been considered for the database to take account of the viscoelastic behaviour of cartilages. 
Typically, in the inverse design approach the properties of the polymers/composites are used as the input while the output is the most suitable composites to be used in the intended applications. In this study, the input is the numerical range of the selected properties, and the output is found as a categorical variable (i.e., string or the text). For this purpose, the scattered plots have been plotted in Figs. 6-8 to represent the raw data for tensile modulus, tensile strength and elongation at break, respectively. It is to note that the database has been created based on the list of the polymers/composites most recurrently used in cartilages repair. The raw data retrieved from the data bases consisted of outliers that were needed to be screened/removed before running the machine learning algorithms. After cleaning the outliers, the most concentrated data zones were selected for all three properties of interest. As shown in Fig. 7, the tensile strength data is so concentrated that they almost formed a straight line, whereas the tensile modulus and elongation data shown in Figs. 6 and 8 were little more scattered. The blue rectangular boxes shown in each of the Figs. 6-8 represents the numerical ranges of tensile modulus, tensile strength and elongation, respectively. Upon cleaning up of the outliers, the magnitude range of the tensile modulus, tensile strength and elongation were found to be 0-2 GPa, 0-0.2 GPa and 0-400\%, respectively. These ranges are in agreement with the mechanical properties of human cartilages presented in Table 3.

\section{Machine Learning Algorithms:}

\section{Random forest regression}

Random forest regression is a supervised machine learning technique that predicts the data by classification or regression. It uses decision trees to predict the most optimum outputs. The random forest regression is done in three steps, and the first step involves randomly bootstrapping the samples, followed by the creation of multiple randomized trees. Finally, the prediction is retrieved from each of the tree hierarchically and the task decision is made to retrieve final outputs[51, 69, 70].

In this study, the random forest regression data consisted of the numerical input and the categorical response variables (i.e., outputs), which later can be converted to the numerical format. The training set was fed into the machine learning algorithm and several trials were run. The regression trees were developed multiple times until a minimum mean square error was obtained. A plot was developed which showed how the error varies with the increase of the number of trees (n). As shown in Fig. 9, for all three properties of interest (i.e., tensile modulus, tensile strength, elongation at break) initially the errors varied and then stabilized. From Fig. 9 (a), (b) and (c), it is evident that the number of trees ( $n$ ) that is enough to stabilize the error is about 250, 250 and 500 for tensile modulus, tensile strength, elongation at break, respectively[71, 72]. Since there was a large variation of values of elongation, the extra step of scaling was carried out. As the errors have been stabilized for all three input properties, machine is then ready to predict the desired outputs.

On receiving the minimum mean square error for the training set, the testing set is then fed to the random forest regression algorithm to predict the outputs. Then the predicted output(s) were compared with the observed data to create the residual plots (shown in Fig. 10). On plotting the residual data, from Fig. 10 it is evident that the distribution of the predicted vs observed values of the properties of interest fitted 
substantially. There is a robust linear relationship between the predicted and the observed values for all of the three properties related to the mechanical strength of the cartilage substitutes.

The final step includes predicting the best polymers/composites for cartilage repair (as the output) by using the mechanical properties of the natural cartilages (i.e., tensile modulus, tensile strength at yield, and elongation at break) as the input. Depending on the extent of the cartilage damage, some certain mechanical property may become more important than others[73]. However, to be qualified as the clinically successful cartilages, the biomaterials should satisfy the biomechanical requirements[74-76]. As the load bearing is the main function of the articular cartilages, their tensile biomechanical properties (i.e., tensile modulus, tensile strength, strain at fracture etc.) are particularly crucial[ $74,77,78]$. Given that for some patients the tensile modulus of the developed composites may need to be matched with that of the articular cartilages, while for some other patient the tensile strength or elongation of the composites may be the most critical property to look up to. Due to that, initially the machine learning algorithm has been run for single property, followed by the combination of two and three properties. For each of this case, the predicted results have been summarized in the Table 4, which includes the mean square error of the modeled data, \% variation explained and the predicted output (polymers/composites with ranks). The error was brought down to its minimum value from the mean square error for 500 random forest regression trees (as shown in Fig. 10). $\mathrm{R}$ square indicates the variance present in the dependent variables (the output-the name of the polymers/composites) or its extent of moderation[79, 80]. The R square value for all the fitted data was found to be less than $50 \%$, which is reasonable for the categorical type of dependent variable[81, 82]. Typically, the $\mathrm{R}$ square value can be found much less than $50 \%$ when it is to deal with the categorical variables. Smith et al[81] evaluated the efficiency of random forest regression in predicting the concentration of neurochemicals with the $R$ square values of as low as 0.49 and 0.27 . In another study, Wang et al[82] studied the cause of death (i.e., a categorical dependent variable) in prostate cancer using the random forest model with $\mathrm{R}$ square $\sim 0.1707$.

While considering only the tensile modulus of the developed cartilage substitutes ( 3 to $100 \mathrm{MPa}$ ), the model (i.e., random forest regression) predicted poly(epsilon-caprolactone) to be the ideal polymer/composite owing to have the tensile modulus in the range of the natural cartilages. The science direct and PubMed were used to investigate whether the predicted output (poly(epsilon-caprolactone) for cartilage tissue engineering) is accurate. Using the model predicted polymers and 'cartilage' as keywords, number of the research articles published for each polymer was extracted and compiled in a pie chart as shown in Fig. 11. Among the predicted output, the poly(epsilon-caprolactone) is the second-highest utilized polymer as the polymer matrix for cartilage repair. Therefore, the prediction made by the random forest regression model is found to be in agreement.

Similarly, the random forest regression model predicted the polymers/composites using the tensile strength at yield and elongation at break as separate testing inputs. According to Table 3 , the tensile strength at yield and elongation at break of the natural cartilages are $35 \mathrm{MPa}$ and 2-140\%, respectively. Therefore, these numerical values were set as the testing inputs to predict the polymers/composites that are most suitable for cartilage repair. The model predicted that the polymer(s)/composites which are 
more likely to fit with set tensile strength and elongation at break of the articular cartilages are poly(lactic acid)/poly[ethene-co-(vinyl acetate)] and poly(dodecano-12-lactam), respectively. To support these predictions, Fig. 11 displayed that poly(lactic acid), poly[ethene-co-(vinyl acetate)] and poly(dodecano-12lactam) appeared 6214, 548, 106 times in PubMed and ScienceDirect databases for cartilage tissue engineering.

In addition to the single property optimization, multi-property optimization has also been carried out using random forest regression model. The model was found to predict poly(epsiloncaprolactone)/poly(bisphenol A carbonate) blend (Table 4) as the best composites for cartilages substitutes while tensile modulus and tensile strength at yield of the natural cartilages were set as the testing input. Interestingly, the same polymer blend (i.e., poly(epsilon-caprolactone)/poly(bisphenol A carbonate)) was found to be the most suitable candidate for cartilage repair when all three properties of natural cartilages were used as the input. According to ScienceDirect and PubMed databases for the period past 10 years, poly(epsilon-caprolactone) and poly(bisphenol A carbonate) have been used as polymer matrix for the cartilage repair for 1667 and 132 times, respectively (Fig. 11). Few other combinations of multi-variable optimization have been modeled and summarized in Table 4. Among of the outputs, few of the predicted blends, such as, poly(epsilon-caprolactone)/poly (bisphenol A carbonate) or poly(lactic acid)/poly[ethene-co-(vinyl acetate)] are not that much popular in cartilage; however, these polymers individually are widely used in the development of cartilages[83-85].

Poly(lactic acid) and poly(epsilon-caprolactone) are the most widely used composites in cartilage repair $[86,87]$, owing to their superior mechanical integrity (i.e., viscoelasticity), remarkable biodegradability, biocompatibility and bioabsorbability. Even on degradation, their byproducts are non-toxic in nature[86, 88-91]. These two polymers belong to the nylon group (poly(dodecano-12-lactam) and 2) poly(hexano-6lactam)). They possess most of the attributes required to perform as the scaffold for cartilages. Their chemical structure is yet another attractive feature, and its active groups are similar to those of the collagen[92-94].

More importantly, all of the random forest regression outputs (i.e., polymer(s)/composites) listed in Table 4 possess excellent thermomechanical and viscoelastic properties. Each of these polymer(s)/composites has been proven as the ideal candidates to facilitate the growth and proliferation into the chondrogenic differentiation required for cartilage repair[95]. Several reports confirmed that due to their thermomechanical strength and biocompatibility, most of these polymers/composites (Table 4) have been approved by the FDA to be used in other fields of tissue engineering[44, 45, 96, 97].

\section{Multinomial logistic regression (MNLR):}

In this study, numerical independent variables (i.e., inputs) and categorical response variables (i.e., the outputs) were used. Indeed, the response variables were ninety-seven different polymers/composites, and consist of multiple levels; hence, the multinomial logistic regression (MNLR) was deemed to be suitable for modelling the response variables as factors $[58,98,99]$. The numerical factors were at two levels, and it consisted of a range of minimum and maximum values of the tensile strength at yield, tensile modulus, 
and elongation at break. The input was either an individual factor or a combination of multiple factors. For example, taking the tensile modulus of composites as the input (i.e., single factor), the training data sets are modelled. After modeling with the training data, the range of the tensile modulus of the cartilages are used as the testing input to predict the best polymer blends owing to have similar properties of the cartilages. The response variables were found to be the blends of poly (glycolic acid)//poly(lactic acid) and poly(methyl methacrylate)//poly(epsilon-caprolactone) (as shown in Table 5).

The goodness-of-fit model was assessed by comparing its residual deviance $\left(D_{m}=-2 L L_{m}=1466.6345\right)$ with the null hypothesis residual deviance for the model $\left(D_{0}=-2 L L_{0}=1763.898\right)$, which includes only the intercepts. The deviance is a measure of how poorly the model reproduces the observed data. The likelihood ratio test $\left(G=D_{0}-D_{1}=297.26296, d f=94, p<.001\right)$ compares these two deviances. The null hypothesis is rejected, indicating a statistically significant decrease in the deviance when the predictor $(X)$ is included in the model. This means that the model fits the data better than the null model in terms of the correspondence between the observed and predicted conditional probabilities. The goodness-of-fit of modeled data was interpreted utilizing $P$ value, and the residual deviation and its corresponding $P$ value were summarized in Table 6. It is evident from Table 6 that the null hypothesis was rejected for all of the independent variables, and thereby, the $P$ value is significant for all of the parameters $(P<0.05)$.

The MNLR model was run using the neural network pack in $\mathrm{R}$ after 100 iterations[100]. The residual values have been plotted against the fitted values to generate the scatter plot (Fig. 12) while considering all three independent variables (i.e., tensile modulus, tensile strength and elongation at break of the natural cartilages) used in this study. The scatter plot shown in Fig. 8 prove the data independence, homoscedasticity, and linearity. On inserting the tensile modulus of 3-100 MPa, elongation of 2-140\% and the tensile strength of $35 \mathrm{MPa}$ to the already fitted model, the multinomial regression model predicted polyethene/polyethene-graft-poly(maleic anhydride) blend as the most suitable one for the cartilage repair. The predicted results along with the residual deviance for all other individual and combinatory testing inputs are summarized in Table 5.

To confirm whether the predictions made by the MNLR model are accurate and relevant to the cartilage tissue engineering, the predicted polymers/composites' names were chosen as the keywords in the PubMed and ScienceDirect and searched. The search results were summarized in the form of a pie chart, as shown in Fig. 13. It was found that polyethylene and polylactic acid have been mentioned with cartilage tissue engineering 10603 and 6214 times, respectively. Moreover, poly lactic acid and poly caprolactone belong to the group of linear aliphatic polyester polymers[101] and the poly caprolactone is known to increase the cell viability by $20 \%[102]$. Even the byproducts of the degradation of polylactic acid (i.e., water and carbon dioxide) are non-toxic in nature[103]. Moreover, both polypropylene and polyethylene are widely used in developing implants, as they are easy to be molded to the desired shape, and are inexpensive[104-107]. They have been known to initiate a minimal immune response, and have superior mechanical (i.e., viscoelastic) properties and biocompatibility[108-110]. Particularly, both PLA and PCL can be modified to exhibit viscoelastic properties required for mimicking cartilages[111-115]. Moreover, polypropylene has proven to be an excellent candidate in the development of cartilages in the 
nasal reconstructive surgery [116]. Overall, all the polymers/composites mentioned in the pie chart (Fig. 13) have been employed in the field of cartilage tissue engineering[108, 109, 117, 118].

\section{Conclusion}

The design of new biomaterials is a complex, tedious, and time-consuming affair. Designing cartilage substitutes is even more intricate due to their unique properties/functionality and their diverse locations in the human body. Among many, viscoelasticity is one of the most important parameters that need to be taken into serious consideration in designing cartilages. More importantly, the viscoelasticity of the cartilages may not be attributed to any single property, rather it is better represented by a set of mechanical properties such as, tensile strength, tensile modulus, and the elongation at break. Therefore, it is expected that the best polymer matrices/composites to be used in cartilage repair must exhibit these properties as much as in the ranges of the properties of the natural articular cartilages. This study attempts to use inverse design approach by using two machine learning algorithms (i.e., random forest and multinomial logistic regression) to predict the most suitable polymers/composites for cartilage substitutes by using the ranges of the tensile modulus, elongation at break and tensile strength of the natural cartilages as inputs. Both single and multivariable optimization were conducted so that the output was predicted by using both individual and combinatory properties of the cartilages. While considering all three properties of interest, poly(epsilon-caprolactone)/poly(bisphenol A carbonate) and polyethene//polyethene-graft-poly(maleic anhydride) were found to be the best polymer(s)/composites for cartilage repair using the random forest and multinomial logistic regression techniques, respectively. All of the predicted polymer(s)/composites in both machine learning algorithms are FDA approved to be used in cartilages tissue engineering; more importantly they possess the similar tensile biomechanical properties of the natural cartilages, and may only initiate minimal immune responses in the body environment.

However, the limitation of this study lies into the low level of goodness of fit of the modeled data, which is largely attributed to the response variable to be categorical in nature. Different machine learning algorithms may be explored to handle the categorical variable(s) with the multi-levels. Moreover, the biological properties of the natural cartilages may be included as the inputs in the future research, although still there is a lack of appropriate database to correlate the properties of the stem cells linked to the polymer matrix/composites to be used in cartilage repair.

\section{Declarations}

\section{Author contribution}

A.M., A-H.I.M, and M.S.M conceptualized the research idea. A.M. run the machine learning algorithms, and prepared the first draft of the manuscript. A.M., A-H.I.M and M.S.M analysed the results. A-H.I.M, and M.S.M supervised the work. All the authors were involved in scientific discussion of the research work. 


\section{Conflicts of interest}

"There is no conflict to declare".

\section{Acknowledgements}

The authors would like to acknowledge the UAE University for providing funds through its internal research grant (\#31N325-UPAR-6-2017) to carry out this work.

\section{References}

1. Nims RJ, Cigan AD, Durney KM, et al (2017) $\left(^{*}\right)$ Constrained Cage Culture Improves Engineered Cartilage Functional Properties by Enhancing Collagen Network Stability. Tissue Eng Part A 23:847858. https://doi.org/10.1089/ten.TEA.2016.0467

2. Daly AC, Freeman FE, Gonzalez-Fernandez T, et al (2017) 3D Bioprinting for Cartilage and Osteochondral Tissue Engineering. Adv Healthc Mater 6:. https://doi.org/10.1002/adhm.201700298

3. Collins AT, Hu G, Newman H, et al (2021) Obesity alters the collagen organization and mechanical properties of murine cartilage. Sci Rep 11:1626. https://doi.org/10.1038/s41598-020-80599-1

4. Roy HS, Singh R, Ghosh D (2021) Recent advances in nanotherapeutic strategies that target nitric oxide pathway for preventing cartilage degeneration. Nitric Oxide 109-110:1-11. https://doi.org/10.1016/j.niox.2021.01.002

5. Nishimura R, Hata K, Takahata Y, et al (2020) Role of Signal Transduction Pathways and Transcription Factors in Cartilage and Joint Diseases. Int J Mol Sci 21:1340. https://doi.org/10.3390/ijms21041340

6. García-Martínez L, Campos F, Godoy-Guzmán C, et al (2017) Encapsulation of human elastic cartilage-derived chondrocytes in nanostructured fibrin-agarose hydrogels. Histochem Cell Biol 147:83-95. https://doi.org/10.1007/s00418-016-1485-9

7. Anderson DE, Johnstone B (2017) Dynamic Mechanical Compression of Chondrocytes for Tissue Engineering: A Critical Review. Front Bioeng Biotechnol 5:. https://doi.org/10.3389/fbioe.2017.00076

8. Mandelbaum BR, ElAttrache NS (2016) Articular Cartilage Repair Techniques. Sports Med Arthrosc Rev 24:43. https://doi.org/10.1097/JSA.0000000000000114

9. Deng Z, Jin J, Zhao J, Xu H (2015) Cartilage Defect Treatments: With or without Cells? Mesenchymal Stem Cells or Chondrocytes? Traditional or Matrix-Assisted? A Systematic Review and MetaAnalyses. In: Stem Cells Int. https://www.hindawi.com/journals/sci/2016/9201492/. Accessed 17 Aug 2020

10. Ashraf S, Cha B-H, Kim J-S, et al (2016) Regulation of senescence associated signaling mechanisms in chondrocytes for cartilage tissue regeneration. Osteoarthritis Cartilage 24:196-205. https://doi.org/10.1016/j.joca.2015.07.008 
11. Hendren L, Beeson P (2009) A review of the differences between normal and osteoarthritis articular cartilage in human knee and ankle joints. Foot Edinb Scotl 19:171-176.

https://doi.org/10.1016/j.foot.2009.03.003

12. Grossman JP, Lyons MC (2009) A review of osteochondral lesions of the talus. Clin Podiatr Med Surg 26:205-226. https://doi.org/10.1016/j.cpm.2009.01.003

13. Mourad A-HI, Akkad RO, Soliman AA, Madkour TM (2009) Characterisation of thermally treated and untreated polyethylene-polypropylene blends using DSC, TGA and IR techniques. Plast Rubber Compos 38:265-278. https://doi.org/10.1179/146580109X12473409436625

14. McCreery KP, Calve S, Neu CP (2020) Ontogeny informs regeneration: explant models to investigate the role of the extracellular matrix in cartilage tissue assembly and development. Connect Tissue Res 61:278-291. https://doi.org/10.1080/03008207.2019.1698556

15. Rathan S, Dejob L, Schipani R, et al (2019) Fiber Reinforced Cartilage ECM Functionalized Bioinks for Functional Cartilage Tissue Engineering. Adv Healthc Mater 8:1801501.

https://doi.org/10.1002/adhm.201801501

16. Mourad A-HI, Abdel-Magid BM, El-Maaddawy T, Grami ME (2010) Effect of Seawater and Warm Environment on Glass/Epoxy and Glass/Polyurethane Composites. Appl Compos Mater 17:557573. https://doi.org/10.1007/s10443-010-9143-1

17. Zhou Z, Wu W, Fang J, Yin J (2020) Polymer-based porous microcarriers as cell delivery systems for applications in bone and cartilage tissue engineering. Int Mater Rev 0:1-37. https://doi.org/10.1080/09506608.2020.1724705

18. Chen L, Liu J, Guan M, et al (2020) <p>Growth Factor and Its Polymer Scaffold-Based Delivery System for Cartilage Tissue Engineering</p>. In: Int. J. Nanomedicine. https://www.dovepress.com/growth-factor-and-its-polymer-scaffold-based-delivery-system-for-cartipeer-reviewed-fulltext-article-IJN. Accessed 18 Aug 2020

19. Abu-Jdayil B, Mourad A-HI, Hussain A (2016) Investigation on the mechanical behavior of polyesterscrap tire composites. Constr Build Mater 127:896-903. https://doi.org/10.1016/j.conbuildmat.2016.09.138

20. Jassmi HA, Najjar FA, Mourad A-HI (2018) Large-Scale 3D Printing: The Way Forward. IOP Conf Ser Mater Sci Eng 324:012088. https://doi.org/10.1088/1757-899X/324/1/012088

21. Zhang Y, Liu X, Zeng L, et al (2019) Polymer Fiber Scaffolds for Bone and Cartilage Tissue Engineering. Adv Funct Mater 29:1903279. https://doi.org/10.1002/adfm.201903279

22. Asadi N, Alizadeh E, Salehi R, et al (2018) Nanocomposite hydrogels for cartilage tissue engineering: a review. Artif Cells Nanomedicine Biotechnol 46:465-471. https://doi.org/10.1080/21691401.2017.1345924

23. Attarian Shandiz M, Gauvin R (2016) Application of machine learning methods for the prediction of crystal system of cathode materials in lithium-ion batteries. Comput Mater Sci 117:270-278. https://doi.org/10.1016/j.commatsci.2016.02.021 
24. Chen C-T, Gu GX (2020) Generative Deep Neural Networks for Inverse Materials Design Using Backpropagation and Active Learning. Adv Sci 7:1902607. https://doi.org/10.1002/advs.201902607

25. Silwattananusarn T, Tuamsuk K (2012) Data Mining and Its Applications for Knowledge Management: A Literature Review from 2007 to 2012. ArXiv12102872 Cs

26. AbuOmar O, Nouranian S, King R, et al (2013) Data mining and knowledge discovery in materials science and engineering: A polymer nanocomposites case study. Adv Eng Inform 27:615-624. https://doi.org/10.1016/j.aei.2013.08.002

27. Moot T, Isayev O, Call RW, et al (2016) Material informatics driven design and experimental validation of lead titanate as an aqueous solar photocathode. Mater Discov 6:9-16. https://doi.org/10.1016/j.md.2017.04.001

28. Ramakrishna S, Zhang T-Y, Lu W-C, et al (2019) Materials informatics. J Intell Manuf 30:2307-2326. https://doi.org/10.1007/s10845-018-1392-0

29. Moot T, Isayev O, Call RW, et al (2016) Material informatics driven design and experimental validation of lead titanate as an aqueous solar photocathode. Mater Discov 6:9-16. https://doi.org/10.1016/j.md.2017.04.001

30. Kajita S, Ohba N, Jinnouchi R, Asahi R (2017) A Universal 3D Voxel Descriptor for Solid-State Material Informatics with Deep Convolutional Neural Networks. Sci Rep 7:16991. https://doi.org/10.1038/s41598-017-17299-w

31. Kim K, Kang S, Yoo J, et al (2018) Deep-learning-based inverse design model for intelligent discovery of organic molecules. Npj Comput Mater 4:1-7. https://doi.org/10.1038/s41524-018-0128-1

32. Zunger $A(2018)$ Inverse design in search of materials with target functionalities. Nat Rev Chem 2:0121. https://doi.org/10.1038/s41570-018-0121

33. Venkatraman V, Alsberg BK (2018) Designing High-Refractive Index Polymers Using Materials Informatics. Polymers 10:103. https://doi.org/10.3390/polym10010103

34. Le T-T (2020) Prediction of tensile strength of polymer carbon nanotube composites using practical machine learning method. J Compos Mater 0021998320953540. https://doi.org/10.1177/0021998320953540

35. Kim B, Lee S, Kim J (2020) Inverse design of porous materials using artificial neural networks. Sci Adv 6:eaax9324. https://doi.org/10.1126/sciadv.aax9324

36. Garcovich D, Marques Martinez L, Adobes Martin M (2020) Citation classics in paediatric dentistry: a bibliometric study on the 100 most-cited articles. Eur Arch Paediatr Dent 21:249-261. https://doi.org/10.1007/s40368-019-00483-z

37. Yu D, He X (2020) A bibliometric study for DEA applied to energy efficiency: Trends and future challenges. Appl Energy 268:115048. https://doi.org/10.1016/j.apenergy.2020.115048

38. Teoh SH (2000) Fatigue of biomaterials: a review. Int J Fatigue 22:825-837. https://doi.org/10.1016/S0142-1123(00)00052-9 
39. Qu H, Fu H, Han Z, Sun Y (2019) Biomaterials for bone tissue engineering scaffolds: a review. RSC Adv 9:26252-26262. https://doi.org/10.1039/C9RA05214C

40. Kerin AJ, Wisnom MR, Adams MA (2016) The compressive strength of articular cartilage: Proc Inst Mech Eng [H]. https://doi.org/10.1243/0954411981534051

41. Sophia Fox AJ, Bedi A, Rodeo SA (2009) The basic science of articular cartilage: structure, composition, and function. Sports Health 1:461-468. https://doi.org/10.1177/1941738109350438

42. Cole BJ, Malek MM (2013) Articular Cartilage Lesions: A Practical Guide to Assessment and Treatment. Springer Science \& Business Media

43. DirSci MN, PhD VHFM (2012) Basic Biomechanics of the Musculoskeletal System, Fourth, North American edition. LWW, Philadelphia

44. Nordin M, Frankel VH (2012) Basic Biomechanics of the Musculoskeletal System. Wolters Kluwer/Lippincott Williams \& Wilkins Health

45. Bellucci G (2001) Mechanical behaviour of articular cartilage under tensile cyclic load. Rheumatology 40:1337-1345. https://doi.org/10.1093/rheumatology/40.12.1337

46. Izadifar Z, Chen X, Kulyk W (2012) Strategic Design and Fabrication of Engineered Scaffolds for Articular Cartilage Repair. J Funct Biomater 3:799. https://doi.org/10.3390/jfb3040799

47. Otsuka S, Kuwajima I, Hosoya J, et al (2011) PoLylnfo: Polymer Database for Polymeric Materials Design. In: 2011 International Conference on Emerging Intelligent Data and Web Technologies. pp 22-29

48. Lee M-H (2020) A Machine Learning-Based Design Rule for Improved Open-Circuit Voltage in Ternary Organic Solar Cells. Adv Intell Syst 2:1900108. https://doi.org/10.1002/aisy.201900108

49. Breiman L (2017) Classification and Regression Trees. Routledge

50. Ließ M, Glaser B, Huwe B (2012) Uncertainty in the spatial prediction of soil texture: Comparison of regression tree and Random Forest models. Geoderma 170:70-79. https://doi.org/10.1016/j.geoderma.2011.10.010

51. Li Y, Zou C, Berecibar M, et al (2018) Random forest regression for online capacity estimation of lithium-ion batteries. Appl Energy 232:197-210. https://doi.org/10.1016/j.apenergy.2018.09.182

52. Fischetti T, Lantz B, Abedin J, et al (2016) R: Data Analysis and Visualization. Packt Publishing Ltd

53. Marani A, Nehdi ML (2020) Machine learning prediction of compressive strength for phase change materials integrated cementitious composites. Constr Build Mater 265:120286.

https://doi.org/10.1016/j.conbuildmat.2020.120286

54. Bunn A, Korpela M An introduction to dpIR. 16

55. Liaw A, Wiener M (2001) Classification and Regression by RandomForest. Forest 23:

56. Antipov EA, Pokryshevskaya EB (2012) Mass appraisal of residential apartments: An application of Random forest for valuation and a CART-based approach for model diagnostics. Expert Syst Appl 39:1772-1778. https://doi.org/10.1016/j.eswa.2011.08.077 
57. Ruiz A, Villa N (2008) Storms prediction: Logistic regression vs random forest for unbalanced data. ArXiv08040650 Math Stat

58. Jeune W, Francelino M, de Souza E, et al (2018) Multinomial Logistic Regression and Random Forest Classifiers in Digital Mapping of Soil Classes in Western Haiti

59. Itano K, Ueki K, lizuka T, Kuwatani T (2020) Geochemical Discrimination of Monazite Source Rock Based on Machine Learning Techniques and Multinomial Logistic Regression Analysis. Geosciences 10:63. https://doi.org/10.3390/geosciences 10020063

60. Sweileh WM (2020) Bibliometric analysis of scientific publications on "sustainable development goals" with emphasis on "good health and well-being" goal (2015-2019). Glob Health 16:68. https://doi.org/10.1186/s12992-020-00602-2

61. Yue T, Liu H, Long R, et al (2020) Research trends and hotspots related to global carbon footprint based on bibliometric analysis: 2007-2018. Environ Sci Pollut Res 27:17671-17691. https://doi.org/10.1007/s11356-020-08158-9

62. Vinatier C, Mrugala D, Jorgensen C, et al (2009) Cartilage engineering: a crucial combination of cells, biomaterials and biofactors. Trends Biotechnol 27:307-314. https://doi.org/10.1016/j.tibtech.2009.02.005

63. Vinatier C, Bouffi C, Merceron C, et al (2009) Cartilage tissue engineering: towards a biomaterialassisted mesenchymal stem cell therapy. Curr Stem Cell Res Ther 4:318-329

64. Merceron C, Portron S, Masson M, et al (2010) Cartilage tissue engineering: From hydrogel to mesenchymal stem cells. Biomed Mater Eng 20:159-166. https://doi.org/10.3233/BME-2010-0627

65. van Osch GJVM, Brittberg M, Dennis JE, et al (2009) Cartilage repair: past and future--lessons for regenerative medicine. J Cell Mol Med 13:792-810. https://doi.org/10.1111/j.15824934.2009.00789.x

66. Aria M, Cuccurullo C (2017) bibliometrix: An R-tool for comprehensive science mapping analysis. J Informetr 11:959-975. https://doi.org/10.1016/j.joi.2017.08.007

67. Callaghan JJ (2003) The Adult Knee. Lippincott Williams \& Wilkins

68. Hatton J, Davis GR, Mourad A-HI, et al (2019) Fabrication of Porous Bone Scaffolds Using Alginate and Bioactive Glass. J Funct Biomater 10:15. https://doi.org/10.3390/jfb10010015

69. Lee M-H (2020) A Machine Learning-Based Design Rule for Improved Open-Circuit Voltage in Ternary Organic Solar Cells. Adv Intell Syst 2:1900108. https://doi.org/10.1002/aisy.201900108

70. Lee M-H (2020) Robust random forest based non-fullerene organic solar cells efficiency prediction. Org Electron 76:105465. https://doi.org/10.1016/j.orgel.2019.105465

71. K. J, N. S, S. M, et al (2019) Optimization of EDTA enriched phytoaccumulation of zinc by Ophiopogon japonicus: Comparison of Response Surface, Artificial Neural Network and Random Forest models. Bioresour Technol Rep 7:100265. https://doi.org/10.1016/j.biteb.2019.100265

72. Gholizadeh M, Jamei M, Ahmadianfar I, Pourrajab R (2020) Prediction of nanofluids viscosity using random forest (RF) approach. Chemom Intell Lab Syst 201:104010. 
https://doi.org/10.1016/j.chemolab.2020.104010

73. Xiao Y, Friis EA, Gehrke SH, Detamore MS (2013) Mechanical Testing of Hydrogels in Cartilage Tissue Engineering: Beyond the Compressive Modulus. Tissue Eng Part B Rev 19:403-12. http://dx.doi.org.uaeu.idm.oclc.org/10.1089/ten.teb.2012.0461

74. Richmon JD, Sage AB, Wong VW, et al (2005) Tensile Biomechanical Properties of Human Nasal Septal Cartilage. Am J Rhinol 19:617-622. https://doi.org/10.1177/194589240501900616

75. Roberts CR, Rains JK, Paré PD, et al (1997) Ultrastructure and tensile properties of human tracheal cartilage. J Biomech 31:81-86. https://doi.org/10.1016/S0021-9290(97)00112-7

76. Park SS, Jin H-R, Chi DH, Taylor RS (2004) Characteristics of tissue-engineered cartilage from human auricular chondrocytes. Biomaterials 25:2363-2369.

https://doi.org/10.1016/j.biomaterials.2003.09.019

77. Oinas J, Ronkainen AP, Rieppo L, et al (2018) Composition, structure and tensile biomechanical properties of equine articular cartilage during growth and maturation. Sci Rep 8:11357. https://doi.org/10.1038/s41598-018-29655-5

78. Huang AH, Yeger-McKeever M, Stein A, Mauck RL (2008) Tensile properties of engineered cartilage formed from chondrocyte- and MSC-laden hydrogels. Osteoarthritis Cartilage 16:1074-1082. https://doi.org/10.1016/j.joca.2008.02.005

79. Borishade T, Kehinde O, lyiola O, et al (2018) Dataset on customer experience and satisfaction in healthcare sector of Nigeria. Data Brief 20:1850-1853. https://doi.org/10.1016/j.dib.2018.06.070

80. Degger $\mathrm{CMH}$ Discrepancies in neuroradiology. 33

81. Smith PF, Ganesh S, Liu P (2013) A comparison of random forest regression and multiple linear regression for prediction in neuroscience. J Neurosci Methods 220:85-91. https://doi.org/10.1016/j.jneumeth.2013.08.024

82. Wang J, Deng F, Zeng F, et al (2020) Predicting long-term multicategory cause of death in patients with prostate cancer: random forest versus multinomial model. Am J Cancer Res 10:1344-1355

83. Smeriglio P, Lai JH, Yang F, Bhutani N (2015) 3D Hydrogel Scaffolds for Articular Chondrocyte Culture and Cartilage Generation. United States

84. Rosenzweig DH, Carelli E, Steffen T, et al (2015) 3D-Printed ABS and PLA Scaffolds for Cartilage and Nucleus Pulposus Tissue Regeneration. Int J Mol Sci 16:15118-15135.

https://doi.org/10.3390/ijms160715118

85. Zhang Z-Z, Wang S-J, Zhang J-Y, et al (2017) 3D-Printed Poly(epsilon-caprolactone) Scaffold Augmented With Mesenchymal Stem Cells for Total Meniscal Substitution: A 12- and 24-Week Animal Study in a Rabbit Model. Am J Sports Med 45:1497-1511.

https://doi.org/10.1177/0363546517691513

86. Fattahi F (2020) Poly (Lactic Acid) Nano-structures for Cartilage Regeneration and Joint Repair: Strategies and Ideas 
87. Neves SC, Moreira Teixeira LS, Moroni L, et al (2011) Chitosan/poly(epsilon-caprolactone) blend scaffolds for cartilage repair. Biomaterials 32:1068-1079.

https://doi.org/10.1016/j.biomaterials.2010.09.073

88. Abedalwafa M, Wang F, Wang L, Li C BIODEGRADABLE POLY-EPSILON-CAPROLACTONE (PCL) FOR TISSUE ENGINEERING APPLICATIONS: A REVIEW. 18

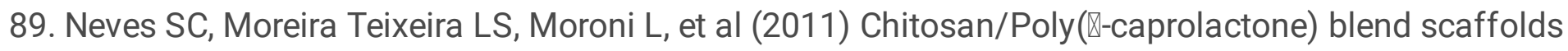
for cartilage repair. Biomaterials 32:1068-1079. https://doi.org/10.1016/j.biomaterials.2010.09.073

90. Theodoridis K, Aggelidou E, Manthou M, et al (2019) Assessment of cartilage regeneration on 3D collagen-polycaprolactone scaffolds: Evaluation of growth media in static and in perfusion bioreactor dynamic culture. Colloids Surf B Biointerfaces 183:110403.

https://doi.org/10.1016/j.colsurfb.2019.110403

91. Hutmacher DW, Goh JCH, Teoh SH (2001) An Introduction to Biodegradable Materials for Tissue Engineering Applications. 30:9

92. Wang H, Li Y, Zuo Y, et al (2007) Biocompatibility and osteogenesis of biomimetic nanohydroxyapatite/polyamide composite scaffolds for bone tissue engineering. Biomaterials 28:33383348. https://doi.org/10.1016/j.biomaterials.2007.04.014

93. Pant HR, Kim CS (2013) Electrospun gelatin/nylon-6 composite nanofibers for biomedical applications. Polym Int 62:1008-1013. https://doi.org/10.1002/pi.4380

94. Guo T, Tian X, Li B, et al (2017) Repair of articular cartilage and subchondral defects in rabbit knee joints with a polyvinyl alcohol/nano-hydroxyapatite/polyamide 66 biological composite material. J Orthop Surg 12:176. https://doi.org/10.1186/s13018-017-0666-0

95. Werkmeister JA, Adhikari R, White JF, et al (2010) Biodegradable and injectable cure-on-demand polyurethane scaffolds for regeneration of articular cartilage. Acta Biomater 6:3471-3481. https://doi.org/10.1016/j.actbio.2010.02.040

96. Giemza B, Domański M, Deliś M, Kapica D (2018) Tribological properties of 3D printed components. J KONBiN 48:447-463. https://doi.org/10.2478/jok-2018-0066

97. Vinyas M, Athul SJ, Harursampath D, Thoi TN (2019) Experimental evaluation of the mechanical and thermal properties of 3D printed PLA and its composites. Mater Res Express 6:115301. https://doi.org/10.1088/2053-1591/ab43ab

98. Petrucci CJ (2009) A Primer for Social Worker Researchers on How to Conduct a Multinomial Logistic Regression. J Soc Serv Res 35:193-205. https://doi.org/10.1080/01488370802678983

99. Böhning D (1992) Multinomial logistic regression algorithm. Ann Inst Stat Math 44:197-200. https://doi.org/10.1007/BF00048682

100. McCaffrey BJ, 11/10/2016 Neural Networks Using the R nnet Package -. In: Vis. Studio Mag. https://visualstudiomagazine.com/articles/2016/11/01/using-the-r-nnet-package.aspx. Accessed 5 Jan 2021

101. Patrício T, Bártolo P (2013) Thermal Stability of PCL/PLA Blends Produced by Physical Blending Process. Procedia Eng 59:292-297. https://doi.org/10.1016/j.proeng.2013.05.124 
102. Baptista R, Guedes M (2021) Morphological and mechanical characterization of 3D printed PLA scaffolds with controlled porosity for trabecular bone tissue replacement. Mater Sci Eng C 118:111528. https://doi.org/10.1016/j.msec.2020.111528

103. Weijie Z, Zhuo C, Sujuan M, et al (2016) Cistanche polysaccharide (CDPS)/polylactic acid (PLA) scaffolds based coaxial electrospinning for vascular tissue engineering. Int J Polym Mater Polym Biomater 65:38-46. https://doi.org/10.1080/00914037.2015.1055629

104. Mourad A-H, Mozumder M, Mairpady A, et al (2017) On the Injection Molding Processing Parameters of HDPE-TiO2 Nanocomposites. Materials 10:85. https://doi.org/10.3390/ma10010085

105. Mozumder MS, Mairpady A, Mourad A-HI (2019) HDPE/TiO2 Nanocomposite: Fabrication and Optimization of Mechanical Property by RSM and ANN. Solid State Phenom 287:54-58. https://doi.org/10.4028/www.scientific.net/SSP.287.54

106. Mozumder MS, Mourad A-HI, Mairpady A, et al (2018) Effect of TiO2 Nanofiller Concentration on the Mechanical, Thermal and Biological Properties of HDPE/TiO2 Nanocomposites. J Mater Eng Perform 27:2166-2181. https://doi.org/10.1007/s11665-018-3305-y

107. Mozumder MS, Mairpady A, Mourad A-HI (2017) Polymeric nanobiocomposites for biomedical applications. J Biomed Mater Res B Appl Biomater 105:1241-1259. https://doi.org/10.1002/jbm.b.33633

108. Remya NS, Nair PD (2013) Engineering cartilage tissue interfaces using a natural glycosaminoglycan hydrogel matrix - An in vitro study. Mater Sci Eng C 33:575- 582. https://doi.org/10.1016/j.msec.2012.09.015

109. Ciorba A, Martini A (2006) Tissue engineering and cartilage regeneration for auricular reconstruction. Int J Pediatr Otorhinolaryngol 70:1507-1515. https://doi.org/10.1016/j.ijporl.2006.03.013

110. Barkhad MS, Abu-Jdayil B, Mourad AHI, Iqbal MZ (2020) Thermal Insulation and Mechanical Properties of Polylactic Acid (PLA) at Different Processing Conditions. Polymers 12:2091. https://doi.org/10.3390/polym12092091

111. Bernardes GP, Luiz N da R, Santana RMC, Forte MM de C (2020) Influence of the morphology and viscoelasticity on the thermomechanical properties of poly(lactic acid)/thermoplastic polyurethane blends compatibilized with ethylene-ester copolymer. J Appl Polym Sci 137:48926. https://doi.org/10.1002/app.48926

112. Kaavessina M, Chafidz A, Ali I, Al-Zahrani SM (2015) Characterization of poly(lactic acid)/hydroxyapatite prepared by a solvent-blending technique: Viscoelasticity and in vitro hydrolytic degradation. J Elastomers Plast 47:753-768. https://doi.org/10.1177/0095244314557973

113. Shahin-Shamsabadi A, Hashemi A, Tahriri M, et al (2018) Mechanical, material, and biological study of a PCL/bioactive glass bone scaffold: Importance of viscoelasticity. Mater Sci Eng C 90:280-288. https://doi.org/10.1016/j.msec.2018.04.080

114. Sundgren N, Bergman G, Shur YJ (1978) Antiplasticization and transition to marked nonlinear viscoelasticity in poly(vinyl chloride) (PVC)/poly-e-caprolactone (PCL) blends. J Appl Polym Sci 22:1255-1265. https://doi.org/10.1002/app.1978.070220508 
115. Izuka A, Winter HH, Hashimoto T (1992) Molecular weight dependence of viscoelasticity of polycaprolactone critical gels. Macromolecules 25:2422-2428.

https://doi.org/10.1021/ma00035a020

116. Ionita S, Popescu S, Lascar I (2015) Polypropylene meshes and other alloplastic implants for soft tissue and cartilage nasal reconstructive surgery - a literature review. Romanian J Rhinol 5:87-94. https://doi.org/10.1515/rjr-2015-0010

117. Li X, Chen S, Li J, et al (2016) 3D Culture of Chondrocytes in Gelatin Hydrogels with Different Stiffness. Polymers 8:. https://doi.org/10.3390/polym8080269

118. Erickson IE, van Veen SC, Sengupta S, et al (2011) Cartilage matrix formation by bovine mesenchymal stem cells in three-dimensional culture is age-dependent. Clin Orthop 469:2744-2753. https://doi.org/10.1007/s11999-011-1869-z

\section{Tables}

Table 1: Top 10 cited papers publications from web of science having cartilage as the keyword from web of science published in year 2005-2020. 


\begin{tabular}{|c|c|c|c|c|}
\hline S. & Title & $\begin{array}{l}\text { Publication } \\
\text { year }\end{array}$ & Citation & $\begin{array}{l}\text { Average } \\
\text { citation/year }\end{array}$ \\
\hline \multirow[t]{2}{*}{1} & Osteoarthritis & 2007 & 759 & 54.21 \\
\hline & By: Goldring, Mary B.; Goldring, Steven R. & & & \\
\hline \multirow[t]{2}{*}{2} & $\begin{array}{l}\text { Chitins and chitosans for the repair of wounded skin, } \\
\text { nerve, cartilage and bone }\end{array}$ & 2009 & 728 & 60.67 \\
\hline & By: Muzzarelli, Riccardo A. A. & & & \\
\hline \multirow[t]{2}{*}{3} & Polymeric materials for bone and cartilage repair & 2010 & 542 & 49.27 \\
\hline & By: Puppi, D.; Chiellini, F.; Piras, A. M.; et al. & & & \\
\hline \multirow[t]{2}{*}{4} & Unlike Bone, Cartilage Regeneration Remains Elusive & 2012 & 447 & 49.67 \\
\hline & $\begin{array}{l}\text { By: Huey, Daniel J.; Hu, Jerry C.; Athanasiou, } \\
\text { Kyriacos A. }\end{array}$ & & & \\
\hline \multirow[t]{2}{*}{5} & Engineering cartilage tissue & 2008 & 447 & 34.38 \\
\hline & By: Chung, Cindy; Burdick, Jason. A. & & & \\
\hline \multirow[t]{2}{*}{6} & $\begin{array}{l}\text { Matrices and scaffolds for delivery of bioactive } \\
\text { molecules in bone and cartilage tissue engineering }\end{array}$ & 2007 & 439 & 31.36 \\
\hline & By: Lee, Soo-Hong; Shin, Heungsoo & & & \\
\hline \multirow[t]{2}{*}{7} & $\begin{array}{l}\text { Repair and tissue engineering techniques for } \\
\text { articular cartilage }\end{array}$ & 2015 & 395 & 65.83 \\
\hline & $\begin{array}{l}\text { By: Makris, Eleftherios A.; Gomoll, Andreas H.; } \\
\text { Malizos, Konstantinos N.; et al. }\end{array}$ & & & \\
\hline \multirow[t]{2}{*}{8} & $\begin{array}{l}\text { Injectable hydrogels for cartilage and bone tissue } \\
\text { engineering }\end{array}$ & 2017 & 361 & 90.25 \\
\hline & By: Liu, Mei; Zeng, Xin; Ma, Chao; et al. & & & \\
\hline \multirow[t]{2}{*}{9} & $\begin{array}{l}\text { Cartilage engineering: a crucial combination of cells, } \\
\text { biomaterials and biofactors }\end{array}$ & 2009 & 285 & 23.75 \\
\hline & $\begin{array}{l}\text { By: Vinatier, Claire; Mrugala, Dorninique; Jorgensen, } \\
\text { Christian; et al. }\end{array}$ & & & \\
\hline \multirow[t]{2}{*}{10} & $\begin{array}{l}\text { Biopolymer-Based Hydrogels for Cartilage Tissue } \\
\text { Engineering }\end{array}$ & 2011 & 283 & 28.30 \\
\hline & By: Balakrishnan, Biji; Banerjee, R. & & & \\
\hline
\end{tabular}

Table 2: Overall database of polymers used in cartilage tissue engineering from Polylnfo database. 


\begin{tabular}{|c|c|c|c|}
\hline Polymers/Composites & $\begin{array}{l}\text { TM } \\
\text { (GPa) }\end{array}$ & TS (GPa) & $\begin{array}{l}E \\
(\%)\end{array}$ \\
\hline polystyrene & 1.4 & 0.01913 & 3.5 \\
\hline polystyrene & 4.2 & 0.1048 & 56.48 \\
\hline poly(2-methylstyrene) & 4 & 0.0691 & 3 \\
\hline poly(2-methylstyrene) & 4 & 0.0691 & 3 \\
\hline poly(vinyl alcohol) & 1.4 & 0.049 & 97 \\
\hline poly(vinyl alcohol) & 1.6 & 0.059 & 110 \\
\hline polyacrylonitrile & 5 & 0.075 & 8.5 \\
\hline polyacrylonitrile & 5 & 0.075 & 8.5 \\
\hline poly(N-vinylpyrrolidone) & 0.075 & 0.0332 & 20 \\
\hline poly(N-vinylpyrrolidone) & 0.075 & 0.0332 & 20 \\
\hline poly(methyl methacrylate) & 1.5 & 0.02958 & 2.1 \\
\hline poly(methyl methacrylate) & 3.7 & 0.083 & 6.4 \\
\hline poly(vinyl chloride) & 0.16 & 0.02393 & 4.9 \\
\hline poly(vinyl chloride) & 3.2 & 0.1 & 412.5 \\
\hline poly(1-chloro-2-hexylvinylene) & 0.43 & 0.017 & 240 \\
\hline poly(1-chloro-2-hexylvinylene) & 0.43 & 0.017 & 240 \\
\hline polyethene//polystyrene & 2 & 0.0431 & 17.5 \\
\hline polyethene//polystyrene & 3.3 & 0.0683 & 32.7 \\
\hline polyethene//poly[ethene-co-(vinyl acetate)] & 0.0052 & 0.0044 & 610 \\
\hline polyethene//poly[ethene-co-(vinyl acetate)] & 0.0076 & 0.0076 & 710 \\
\hline polyethene//poly(acrylonitrile-co-butadiene) & 0.3 & 0.007 & 24 \\
\hline polyethene//poly(acrylonitrile-co-butadiene) & 0.45 & 0.0135 & 37 \\
\hline poly[ethene-co-(oct-1-ene)]//poly[ethene-co-(vinyl alcohol)] & 0.035 & 0.004 & 16 \\
\hline poly[ethene-co-(oct-1-ene)]//poly[ethene-co-(vinyl alcohol)] & 1.1 & 0.029 & 1025 \\
\hline $\begin{array}{l}\text { poly[(maleic anhydride)-co-styrene]//poly[ethene-co-(methyl } \\
\text { acrylate)-co-(glycidyl methacrylate)] }\end{array}$ & 0.79 & 0.0309 & 33.6 \\
\hline $\begin{array}{l}\text { poly[(maleic anhydride)-co-styrene]//poly[ethene-co-(methyl } \\
\text { acrylate)-co-(glycidyl methacrylate)] }\end{array}$ & 0.79 & 0.0309 & 33.6 \\
\hline
\end{tabular}


poly(vinyl acetate)//poly(3-hydroxybutyric acid)//poly(3hydroxybutyric acid)

poly(vinyl acetate)//poly(3-hydroxybutyric acid)//poly(3hydroxybutyric acid)

poly(lactic acid)//poly[ethene-co-(vinyl acetate)]

$0.32 \quad 0.02202 \quad 350$

poly(lactic acid)//poly[ethene-co-(vinyl acetate)]

$0.59 \quad 0.0294 \quad 400$

poly(2-ethylhexyl acrylate)//poly(vinyl chloride)

$\begin{array}{lll}0.51 \quad 0.0042 & 1.6\end{array}$

poly(2-ethylhexyl acrylate)//poly(vinyl chloride)

1.

poly(hexano-6-lactam)

0.019

0.0132

5.5

poly(hexano-6-lactam)

2.3

0.0278

10.7

poly[(hexane-1,6-diamine)-alt-(adipic acid)]

$0.25 \quad 0.031$

1.9

poly[(hexane-1,6-diamine)-alt-(adipic acid)]

3.7

0.0932

530

poly(11-aminoundecanoic acid)

0.61

0.0399

300

poly(11-aminoundecanoic acid)

0.98

0.04

340

poly(dodecano-12-lactam)

0.33

0.085

350

poly(dodecano-12-lactam)

0.33

0.085

350

poly(bisphenol A carbonate)

1.3

0.0028

5

poly(bisphenol A carbonate)

3.7

0.082

200

poly(propylene carbonate)

0.2

poly(propylene carbonate)

1.1

0.027

8.2

poly(epsilon-caprolactone)//poly(bisphenol A carbonate)

2.5

0.059

726.8

poly(epsilon-caprolactone)//poly(bisphenol A carbonate)

3.9

0.0583

3.5

poly(hexano-6-lactam)//poly(bisphenol A carbonate)

2.2

0.0692

70

poly(hexano-6-lactam)//poly(bisphenol A carbonate)

2.2

2.2

0.0705

50

poly(lactic acid)//poly(bisphenol A carbonate)

2

poly(lactic acid)//poly(bisphenol A carbonate)

0.0705

50

poly(ethylene-2,5-furandicarboxylate)

2.4

0.063

20.3

poly(ethylene-2,5-furandicarboxylate)

2.5

0.069

87.9

poly(5-hydroxy-3-oxavaleric acid)

2.5

0.041

2.81

poly(5-hydroxy-3-oxavaleric acid)

0.34

0.041

2.81

0.63

0.0283

273

$0.63 \quad 0.0357$

441




\begin{tabular}{|c|c|c|c|}
\hline poly[(butane-1,4-diol)-alt-(succinic acid)] & 0.34 & 0.0335 & 5.2 \\
\hline poly[(butane-1,4-diol)-alt-(succinic acid)] & 0.71 & 0.0399 & 21.9 \\
\hline poly[(butane-1,4-diol)-alt-(terephthalic acid)] & 0.17 & 0.03 & 10 \\
\hline poly[(butane-1,4-diol)-alt-(terephthalic acid)] & 6 & 0.2 & 350 \\
\hline poly(epsilon-caprolactone) & 0.23 & 0.0105 & 25 \\
\hline poly(epsilon-caprolactone) & 0.46 & 0.0275 & 930 \\
\hline poly[(propane-1,3-diol)-alt-(terephthalic acid)] & 0.013 & 0.03 & 360 \\
\hline poly[(propane-1,3-diol)-alt-(terephthalic acid)] & 1.1 & 0.037 & 590 \\
\hline poly(3-hydroxybutyric acid) & 1.3 & 0.0152 & 1.8 \\
\hline poly(3-hydroxybutyric acid) & 1.3 & 0.0152 & 1.8 \\
\hline polyethene//poly(ethylene terephthalate) & 1 & 0.046 & 87 \\
\hline polyethene//poly(ethylene terephthalate) & 2.3 & 0.073 & 386 \\
\hline $\begin{array}{l}\text { poly(prop-1-ene)//poly(ethylene terephthalate)//poly[ethene-co-(5- } \\
\text { ethylidene-2-norbornene)-co-(prop-1-ene)] }\end{array}$ & 0.045 & 0.0041 & 23.2 \\
\hline $\begin{array}{l}\text { poly(prop-1-ene)//poly(ethylene terephthalate)//poly[ethene-co-(5- } \\
\text { ethylidene-2-norbornene)-co-(prop-1-ene)] }\end{array}$ & 0.77 & 0.016 & 132.1 \\
\hline $\begin{array}{l}\text { poly(vinyl chloride)//poly(D,L-2-methyl-2-propyl-3-hydroxypropionic } \\
\text { acid) }\end{array}$ & 0.13 & 0.0072 & 4.8 \\
\hline $\begin{array}{l}\text { poly(vinyl chloride)//poly(D,L-2-methyl-2-propyl-3-hydroxypropionic } \\
\text { acid) }\end{array}$ & 1.9 & 0.0146 & 648 \\
\hline poly(ethylene oxide)//poly(lactic acid) & 0.33 & 0.015 & 135 \\
\hline poly(ethylene oxide)//poly(lactic acid) & 0.76 & 0.036 & 340 \\
\hline poly[(butane-1,4-diol)-alt-(terephthalic acid)]//poly(hexano-6-lactam) & 2.8 & 0.069 & 36 \\
\hline poly[(butane-1,4-diol)-alt-(terephthalic acid)]//poly(hexano-6-lactam) & 2.9 & 0.07 & 38 \\
\hline poly(epsilon-caprolactone)//cellulose & 0.25 & 0.0095 & 6.3 \\
\hline poly(epsilon-caprolactone)//cellulose & 0.35 & 0.0142 & 650 \\
\hline poly(3-hydroxybutyric acid)//poly(lactic acid) & 0.027 & 0.0361 & 3.5 \\
\hline poly(3-hydroxybutyric acid)//poly(lactic acid) & 0.035 & 0.0552 & 27 \\
\hline poly(3-hydroxybutyric acid)//poly[(glycolic acid)-co-(lactic acid)] & 0.51 & 0.012 & 23 \\
\hline poly(3-hydroxybutyric acid)//poly[(glycolic acid)-co-(lactic acid)] & 0.9 & 0.029 & 116 \\
\hline poly(3-hydroxybutyric acid)//poly[(D-lactic acid)-co-(L-lactic acid)] & 0.1 & 0.0016 & 26 \\
\hline
\end{tabular}




\begin{tabular}{|c|c|c|c|}
\hline poly(3-hydroxybutyric acid)//poly[(D-lactic acid)-co-(L-lactic acid)] & 0.8 & 0.012 & 300 \\
\hline polyetheretherketone & 1.3 & 0.031 & 3.8 \\
\hline polyetheretherketone & 8.3 & 0.189 & 496 \\
\hline polyethene & 0.001 & 0.004 & 0.04 \\
\hline polyethene & 3.8 & 0.1887 & 1590 \\
\hline poly(prop-1-ene) & 0.0034 & $1.74 \mathrm{E}-05$ & 1.6 \\
\hline poly(prop-1-ene) & 3 & 0.043 & 1750 \\
\hline poly(but-1-ene) & 0.15 & 0.01 & 240 \\
\hline poly(but-1-ene) & 0.21 & 0.0164 & 320 \\
\hline poly(4-methylpent-1-ene) & 0.021 & 0.0006 & 18 \\
\hline poly(4-methylpent-1-ene) & 0.06 & 0.0018 & 900 \\
\hline polyethene//poly(prop-1-ene)//poly[ethene-co-(prop-1-ene)] & 1.4 & 0.0205 & 200 \\
\hline polyethene//poly(prop-1-ene)//poly[ethene-co-(prop-1-ene)] & 1.5 & 0.024 & 200 \\
\hline $\begin{array}{l}\text { polyethene//polystyrene//polystyrene-block-(hydrogenated } \\
\text { polybutadiene)-block-polystyrene }\end{array}$ & 0.88 & 0.0302 & 4 \\
\hline $\begin{array}{l}\text { polyethene//polystyrene//polystyrene-block-(hydrogenated } \\
\text { polybutadiene)-block-polystyrene }\end{array}$ & 0.99 & 0.0302 & 4 \\
\hline polyethene//poly[ethene-co-(maleic anhydride)] & 2.2 & 0.0151 & 170 \\
\hline polyethene//poly[ethene-co-(maleic anhydride)] & 2.2 & 0.0171 & 340 \\
\hline polyethene//poly[ethylene-co-(but-1-ene)] & $5.8 \mathrm{E}(-1)$ & 0.003 & 360 \\
\hline polyethene//poly[ethylene-co-(but-1-ene)] & $7.8 \mathrm{E}(-1)$ & 0.027 & 1050 \\
\hline polyethene//hydrogenated poly(cyclopenta-1,3-diene) & $5.0 \mathrm{E}(-2)$ & 0.0019 & 2 \\
\hline polyethene//hydrogenated poly(cyclopenta-1,3-diene) & 1.1 & 0.0265 & 250 \\
\hline $\begin{array}{l}\text { polyethene//poly(hexano-6-lactam)//polyethene-graft-poly(maleic } \\
\text { anhydride) }\end{array}$ & $4.2 \mathrm{E}(-2)$ & 0.0237 & 45.5 \\
\hline $\begin{array}{l}\text { polyethene//poly(hexano-6-lactam)//polyethene-graft-poly(maleic } \\
\text { anhydride) }\end{array}$ & 4.9E(-1) & 0.0323 & 413.7 \\
\hline polyethene//polyethene-graft-poly(maleic anhydride) & $9.2 \mathrm{E}(-1)$ & 0.008 & 1.1 \\
\hline polyethene//polyethene-graft-poly(maleic anhydride) & 1.1 & 0.0524 & 821 \\
\hline $\begin{array}{l}\text { poly(prop-1-ene)//poly(hexano-6-lactam)//poly[propylene-graft- } \\
\text { (maleic anhydride)] }\end{array}$ & $9.2 \mathrm{E}(-2)$ & 0.0383 & 5.3 \\
\hline poly(prop-1-ene)//poly(hexano-6-lactam)//poly[propylene-graft- & 4 & 0.051 & 13.5 \\
\hline
\end{tabular}


(maleic anhydride)]

polyethene//polyethene-graft-poly(maleic anhydride)

$9.2 \mathrm{E}(-1) \quad 0.008$

1.1

polyethene//polyethene-graft-poly(maleic anhydride)

$\begin{array}{lll}1.1 & 0.0524 & 821\end{array}$

poly(prop-1-ene)//poly(hexano-6-lactam)//poly[propylene-graft(maleic anhydride)]

$9.2 \mathrm{E}(-2) \quad 0.0383 \quad 5.3$

poly(prop-1-ene)//poly(hexano-6-lactam)//poly[propylene-graft-

4

0.051

13.5

(maleic anhydride)]

poly[ethene-co-(prop-1-ene)]//poly[propylene-graft-(maleic anhydride)]

poly[ethene-co-(prop-1-ene)]//poly[propylene-graft-(maleic anhydride)]

poly(hexano-6-lactam)//poly[ethene-co-(prop-1ene)]//poly[propylene-graft-(maleic anhydride)]

$\begin{array}{lll}1.8 & 0.0272 & 8.7\end{array}$

poly(hexano-6-lactam)//poly[ethene-co-(prop-1ene)]//poly[propylene-graft-(maleic anhydride)]

$\begin{array}{lll}3.1 & 0.0272 \quad 8.7\end{array}$

poly[ethylene-co-(but-1-ene)]//cellulose acetate

$\begin{array}{lll}2 & 0.0079 & 130\end{array}$

poly[ethylene-co-(but-1-ene)]//cellulose acetate

$\begin{array}{lll}2.5 & 0.0079 \quad 130\end{array}$

cellulose//poly[ethylene-co-(but-1-ene)]

$1.2 \mathrm{E}(-1) \quad 0.0117 \quad 50$

cellulose//poly[ethylene-co-(but-1-ene)]

$1.2 \mathrm{E}(-1) \quad 0.0117 \quad 50$

poly(vinylidene fluoride)

$1.6 \mathrm{E}(-1) \quad 0.00945 \quad 20$

poly(vinylidene fluoride)

$1.6 \mathrm{E}(-1) \quad 0.00945 \quad 400$

poly(tetrafluoroethylene)

$2.1 \mathrm{E}(-1) \quad 0.012 \quad 234.4$

poly(tetrafluoroethylene)

$2.5 \mathrm{E}(1) \quad 0.012$

234.4

polychlorotrifluoroethylene

$6.0 \mathrm{E}(-1) \quad 0.02882 \quad 24$

polychlorotrifluoroethylene

$6.0 \mathrm{E}(-1) \quad 0.03861 \quad 90$

poly(methyl methacrylate)//poly(vinyl chloride)

$\begin{array}{lll}1.5 & 0.0683 \quad 6.2\end{array}$

poly(methyl methacrylate)//poly(vinyl chloride)

$\begin{array}{lll}1.9 & 0.0732 \quad 9.8\end{array}$

poly(ethylene oxide)

$3.2 \quad 0.006895 \quad 700$

poly(ethylene oxide)

3.4

0.010341200

poly[(glycolic acid)-co-(lactic acid)]

$2.0 \mathrm{E}(-1) \quad 0.043 \quad 0.84$

poly[(glycolic acid)-co-(lactic acid)]

$5.0 \mathrm{E}(-1) \quad 0.052$

14

poly(glycolic acid)//poly(lactic acid)

$2.8 \mathrm{E}(-3)$

3




\begin{tabular}{|c|c|c|c|}
\hline poly(glycolic acid)//poly(lactic acid) & 1.9 & 0 & 56 \\
\hline poly(lactic acid)//poly[(glycolic acid)-co-(lactic acid)] & 0.6 & 0 & 1.6 \\
\hline poly(lactic acid)//poly[(glycolic acid)-co-(lactic acid)] & 1.6 & 0 & 28 \\
\hline poly(methyl methacrylate)//poly(epsilon-caprolactone) & 0.0038 & 0 & 6.3 \\
\hline poly(methyl methacrylate)//poly(epsilon-caprolactone) & 0.001 & 0 & 6.7 \\
\hline poly(vinyl chloride)//poly(epsilon-caprolactone) & 3.7E(-1) & 0 & 136 \\
\hline poly(vinyl chloride)//poly(epsilon-caprolactone) & $3.9 \mathrm{E}(-1)$ & 0 & 470 \\
\hline poly(epsilon-caprolactone)//poly(lactic acid) & 0.0023 & 0.0472 & 3 \\
\hline poly(epsilon-caprolactone)//poly(lactic acid) & 1.2 & 0.0554 & 288 \\
\hline poly(lactic acid)//cellulose acetate & 0.3 & 0.000491 & 26 \\
\hline poly(lactic acid)//cellulose acetate & 1.3 & 0.00075 & 51 \\
\hline poly(lactic acid)//chitin & 0.017 & 0.44 & 11 \\
\hline poly(lactic acid)//chitin & 0.029 & 0.49 & 12.5 \\
\hline poly(prop-1-ene)//poly(prop-1-ene)//poly(hexano-6-lactam) & 0.048 & 0.001042 & 0 \\
\hline poly(prop-1-ene)//poly(prop-1-ene)//poly(hexano-6-lactam) & 0.05 & 0.01688 & 0 \\
\hline poly(prop-1-ene)//polystyrene & 0.25 & 0.005 & 0 \\
\hline poly(prop-1-ene)//polystyrene & 0.21 & 0.0309 & 0 \\
\hline poly(prop-1-ene)//poly(methyl methacrylate) & 0.84 & 0.034 & 4 \\
\hline poly(prop-1-ene)//poly(methyl methacrylate) & 2.6 & 0.038 & 1000 \\
\hline poly(prop-1-ene)//poly(vinyl chloride) & 0 & 0 & 14 \\
\hline poly(prop-1-ene)//poly(vinyl chloride) & 0 & 0 & 23 \\
\hline poly(lactic acid) & 0.26 & 0 & 1 \\
\hline poly(lactic acid) & 0.66 & 0 & 2654 \\
\hline poly(ethylene oxide)//poly[(glycolic acid)-co-(lactic acid)] & 0.0035 & 0 & 0.83 \\
\hline poly(ethylene oxide)//poly[(glycolic acid)-co-(lactic acid)] & 2.17 & 0 & 1.93 \\
\hline polyethene//poly(prop-1-ene) & 0.03 & 0 & 5 \\
\hline polyethene//poly(prop-1-ene) & 0.13 & 0 & 950 \\
\hline poly(prop-1-ene)//poly(dodecano-12-lactam) & 1.3 & 0 & 15 \\
\hline poly(prop-1-ene)//poly(dodecano-12-lactam) & 1.7 & 0 & 23 \\
\hline
\end{tabular}




\begin{tabular}{|c|c|c|c|}
\hline poly(dimethylsiloxane) & 0.00031 & 0 & 9 \\
\hline poly(dimethylsiloxane) & 0.0076 & 0 & 637 \\
\hline poly(pentano-5-lactone) & 0.57 & 0.57 & 150 \\
\hline poly(pentano-5-lactone) & 0.57 & 0.57 & 200 \\
\hline polyformaldehyde & 1 & 0.028 & 20 \\
\hline polyformaldehyde & 3.6 & 0.097 & 380 \\
\hline poly(isobutylene oxide) & 0.81 & 0.03103 & 235 \\
\hline poly(isobutylene oxide) & 0.81 & 0.03103 & 235 \\
\hline poly[ethene-co-(vinyl acetate)] & 0.0038 & 0.003 & 252.2 \\
\hline poly[ethene-co-(vinyl acetate)] & 0.0062 & 0.0059 & 990 \\
\hline poly[ethene-co-(methyl acrylate)] & 0.005 & 0 & 1140 \\
\hline poly[ethene-co-(methyl acrylate)] & 0.005 & 0 & 1140 \\
\hline poly[(glycolic acid)-co-(lactic acid)] & 1.3 & 0.043 & 5 \\
\hline poly[(glycolic acid)-co-(lactic acid)] & 1.9 & 0.052 & 10.8 \\
\hline poly[(D-lactic acid)-co-(L-lactic acid)] & 0.27 & 0.74 & 2.83 \\
\hline poly[(D-lactic acid)-co-(L-lactic acid)] & 1.8 & 0.74 & 317 \\
\hline cellulose acetate & 2 & 0 & 6 \\
\hline cellulose acetate & 2 & 0 & 6 \\
\hline cellulose//amylopectin & 0.56 & 0.011 & 8.4 \\
\hline cellulose//amylopectin & 2.2 & 0.037 & 44 \\
\hline poly[ethene-co-(oct-1-ene)]//poly[ethene-co-(vinyl alcohol)] & 0.035 & 0.0075 & 16 \\
\hline poly[ethene-co-(oct-1-ene)]//poly[ethene-co-(vinyl alcohol)] & 1.1 & 0.0096 & 1025 \\
\hline $\begin{array}{l}\text { poly(prop-1-ene)//poly(hexano-6-lactam)//poly[propylene-graft- } \\
\text { (maleic anhydride)] }\end{array}$ & 1.8 & 0.0383 & 5.3 \\
\hline $\begin{array}{l}\text { poly(prop-1-ene)//poly(hexano-6-lactam)//poly[propylene-graft- } \\
\text { (maleic anhydride)] }\end{array}$ & 3.1 & 0.051 & 13.5 \\
\hline poly[ethylene-co-(but-1-ene)]//poly[ethene-co-(methyl acrylate)] & 0.03 & 0.0055 & 101 \\
\hline poly[ethylene-co-(but-1-ene)]//poly[ethene-co-(methyl acrylate)] & 0.11 & 0.0121 & 608 \\
\hline polyethene//polystyrene & 0.2 & 0.0251 & 4.3 \\
\hline polyethene//polystyrene & 3.3 & 0.0316 & 60 \\
\hline
\end{tabular}


poly(lactic acid)//poly[ethene-co-(vinyl acetate)]

1.1

poly(lactic acid)//poly[ethene-co-(vinyl acetate)]

1.8

0.0285

1

21.9

poly[ethene-co-(vinyl alcohol)]

0.88

0.0331

21.9

poly[ethene-co-(vinyl alcohol)]

3.8

0.055

40

210

Table 3: The properties of articular cartilages (i.e., the target properties of this study)

\begin{tabular}{|lll|}
\hline Properties & Numerical value & Reference \\
\hline Elongation of facture & 2 to $140 \%$ & {$[45]$} \\
\hline Tensile strength & $\sim 35 \mathrm{MPa}$ & {$[42,46]$} \\
\hline Tensile Modulus & 3 to $100 \mathrm{MPa}$ & {$[43]$} \\
\hline
\end{tabular}

Table 4: The predicted outputs (i.e., polymers/composites) from the Random forest regression modeling. 


\begin{tabular}{|c|c|c|}
\hline Properties & Prediction & $\begin{array}{l}\text { Modeling } \\
\text { parameter }\end{array}$ \\
\hline \multirow[t]{3}{*}{ Tensile modulus } & \multirow[t]{3}{*}{ 1) poly(epsilon-caprolactone) } & MSE: 1075.514 \\
\hline & & $\begin{array}{l}\text { \% Var } \\
\text { explained: } \\
-40.99\end{array}$ \\
\hline & & $\begin{array}{l}\text { Rsquare: } \\
0.4135\end{array}$ \\
\hline \multirow[t]{3}{*}{ Tensile strength } & \multirow{3}{*}{$\begin{array}{l}\text { 1) poly(lactic acid)//poly[ethene-co-(vinyl } \\
\text { acetate)] }\end{array}$} & MSE: 807.9401 \\
\hline & & $\begin{array}{l}\% \text { Var } \\
\text { explained: }-6.61\end{array}$ \\
\hline & & $\begin{array}{l}\text { Rsquare : } \\
0.06712\end{array}$ \\
\hline \multirow[t]{3}{*}{ Elongation at break } & 1) poly(dodecano-12-lactam) & MSE: 915.6312 \\
\hline & 2) poly(5-hydroxy-3-oxavaleric acid) & $\begin{array}{l}\text { \% Var } \\
\text { explained: } \\
-20.82\end{array}$ \\
\hline & & $\begin{array}{l}\text { Rsquare: } \\
0.2081950\end{array}$ \\
\hline \multirow{3}{*}{$\begin{array}{l}\text { Tensile modulus + Tensile } \\
\text { strength }\end{array}$} & \multirow{3}{*}{$\begin{array}{l}\text { 1) poly(epsilon- } \\
\text { caprolactone)//poly(bisphenol A carbonate) }\end{array}$} & MSE: 667.2127 \\
\hline & & $\begin{array}{l}\text { \% Var } \\
\text { explained: } \\
11.96\end{array}$ \\
\hline & & Rsquare: 0.1029 \\
\hline \multirow[t]{3}{*}{ Tensile modulus+ Elongation } & 1) poly[(butane-1,4-diol)-alt-(succinic acid)] & $\begin{array}{l}\text { MSE: } \\
718.6268\end{array}$ \\
\hline & \multirow[t]{2}{*}{$\begin{array}{l}\text { 2) poly(lactic acid)//poly(bisphenol A } \\
\text { carbonate) }\end{array}$} & $\begin{array}{l}\text { \% Var } \\
\text { explained: } 5.18\end{array}$ \\
\hline & & $\begin{array}{l}\text { Rsquare: } \\
0.03898\end{array}$ \\
\hline \multirow[t]{3}{*}{ Tensile strength+ Elongation } & 1) poly(bisphenol A carbonate) & MSE: 730.3276 \\
\hline & \multirow[t]{2}{*}{$\begin{array}{l}\text { 2) poly(hexano-6-lactam)//poly(bisphenol } \\
\text { A carbonate) }\end{array}$} & $\begin{array}{l}\text { \% Var } \\
\text { explained: } 3.63\end{array}$ \\
\hline & & $\begin{array}{l}\text { Rsquare: : } \\
0.01542\end{array}$ \\
\hline $\begin{array}{l}\text { Tensile modulus+ Tensile } \\
\text { strength+ Elongation }\end{array}$ & $\begin{array}{l}\text { 1) poly(epsilon- } \\
\text { caprolactone)//poly(bisphenol A carbonate) }\end{array}$ & $\begin{array}{l}\text { MSE: } \\
718.6268\end{array}$ \\
\hline
\end{tabular}


Table 5: Predicted outputs (i.e., polymers/composites) from the multinomial logistic regression modeling. 


\begin{tabular}{|c|c|c|}
\hline Parameter(s) & Properties & Prediction \\
\hline \multirow[t]{3}{*}{ Tensile modulus } & \multirow{2}{*}{$\begin{array}{l}\text { Residual } \\
\text { Deviance: } \\
618.4709\end{array}$} & 1) poly(glycolic acid)//poly(lactic acid) \\
\hline & & $\begin{array}{l}\text { 2) poly(methyl methacrylate)//poly(epsilon- } \\
\text { caprolactone) }\end{array}$ \\
\hline & AIC: 994.4709 & \\
\hline \multirow[t]{2}{*}{ Tensile strength at yield } & $\begin{array}{l}\text { Residual } \\
\text { Deviance: } \\
1410.82\end{array}$ & \multirow[t]{2}{*}{ 1) poly(lactic acid) } \\
\hline & AIC: 1786.82 & \\
\hline \multirow[t]{3}{*}{ Elongation at break } & \multirow{2}{*}{$\begin{array}{l}\text { Residual } \\
\text { Deviance: } \\
1460.5\end{array}$} & \multirow{3}{*}{$\begin{array}{l}\text { 1) poly(lactic acid) } \\
\text { 2) poly(prop-1-ene)//poly(ethylene } \\
\text { terephthalate)//poly[ethene-co-(5-ethylidene-2- } \\
\text { norbornene)-co-(prop-1-ene)] }\end{array}$} \\
\hline & & \\
\hline & AIC: 2212.5 & \\
\hline \multirow{3}{*}{$\begin{array}{l}\text { Tensile modulus and } \\
\text { elongation at break }\end{array}$} & \multirow{2}{*}{$\begin{array}{l}\text { Residual } \\
\text { Deviance: } \\
1186.365\end{array}$} & 1) poly(vinyl chloride) \\
\hline & & $\begin{array}{l}\text { 2) polyethene//polyethene-graft-poly(maleic } \\
\text { anhydride) }\end{array}$ \\
\hline & AIC: 1750.365 & \\
\hline \multirow{3}{*}{$\begin{array}{l}\text { Tensile strength and } \\
\text { elongation at break }\end{array}$} & \multirow{2}{*}{$\begin{array}{l}\text { Residual } \\
\text { Deviance: } \\
1028.616\end{array}$} & 1) poly(isobutylene oxide) \\
\hline & & $\begin{array}{l}\text { 2) polyethene//polyethene-graft-poly(maleic } \\
\text { anhydride) }\end{array}$ \\
\hline & AIC: 1592.616 & \\
\hline \multirow[t]{2}{*}{$\begin{array}{l}\text { Tensile modulus and } \\
\text { Tensile strength }\end{array}$} & $\begin{array}{l}\text { Residual } \\
\text { Deviance: } \\
675.875\end{array}$ & \multirow[t]{2}{*}{ 1) polyethene } \\
\hline & AIC: 1239.875 & \\
\hline \multirow[t]{2}{*}{$\begin{array}{l}\text { Tensile modulus, tensile } \\
\text { strength and elongation } \\
\text { at break }\end{array}$} & $\begin{array}{l}\text { Residual } \\
\text { Deviance: } \\
7.439214\end{array}$ & \multirow[t]{2}{*}{$\begin{array}{l}\text { 1) polyethene//polyethene-graft-poly(maleic } \\
\text { anhydride) }\end{array}$} \\
\hline & AIC: 2212.5 & \\
\hline
\end{tabular}

Table 6: Multinomial logistic regression goodness fit results. 


\begin{tabular}{|c|c|c|c|c|c|}
\hline S. & Model & $\begin{array}{l}\text { Null_Residual } \\
\text { Deviation }\end{array}$ & $\begin{array}{l}\text { Model_Residual } \\
\text { Deviation }\end{array}$ & Df & $\begin{array}{l}P \\
\text { value }\end{array}$ \\
\hline 1 & Tensile modulus & 1763.898 & 1466.635 & 94 & 0 \\
\hline 2 & Tensile strength at yield & 1763.898 & 1419.2 & 94 & $\begin{array}{l}1.34 \mathrm{E}- \\
09\end{array}$ \\
\hline 3 & Elongation at break & 1763.898 & 1564.195 & 94 & 0 \\
\hline 4 & $\begin{array}{l}\text { Tensile modulus and elongation at } \\
\text { break }\end{array}$ & 1763.898 & 1075.018 & 94 & 0 \\
\hline 5 & $\begin{array}{l}\text { Tensile strength and elongation at } \\
\text { break }\end{array}$ & 1763.898 & 1132.967 & 94 & 0 \\
\hline 6 & Tensile modulus and Tensile strength & 1763.898 & 1188.942 & 94 & 0 \\
\hline 7 & $\begin{array}{l}\text { Tensile modulus, tensile strength and } \\
\text { elongation at break }\end{array}$ & 1763.898 & 782.0324 & 94 & 0 \\
\hline
\end{tabular}

\section{Figures}

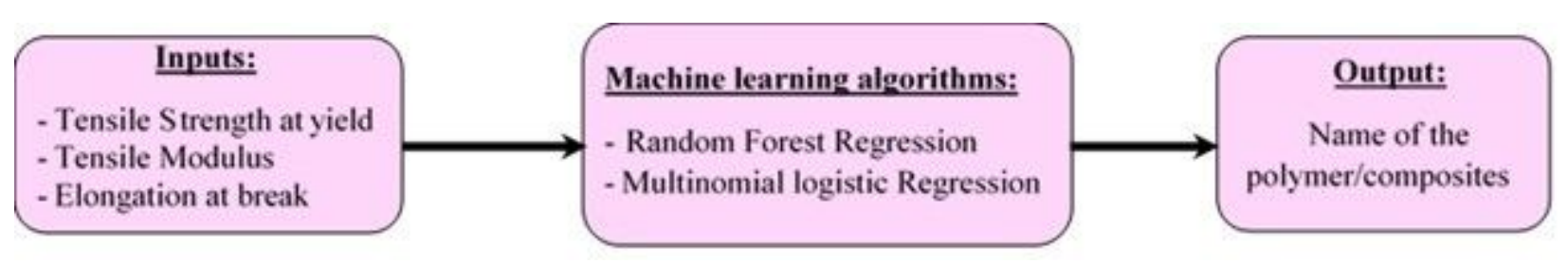

Figure 1

Inverse design approach. 


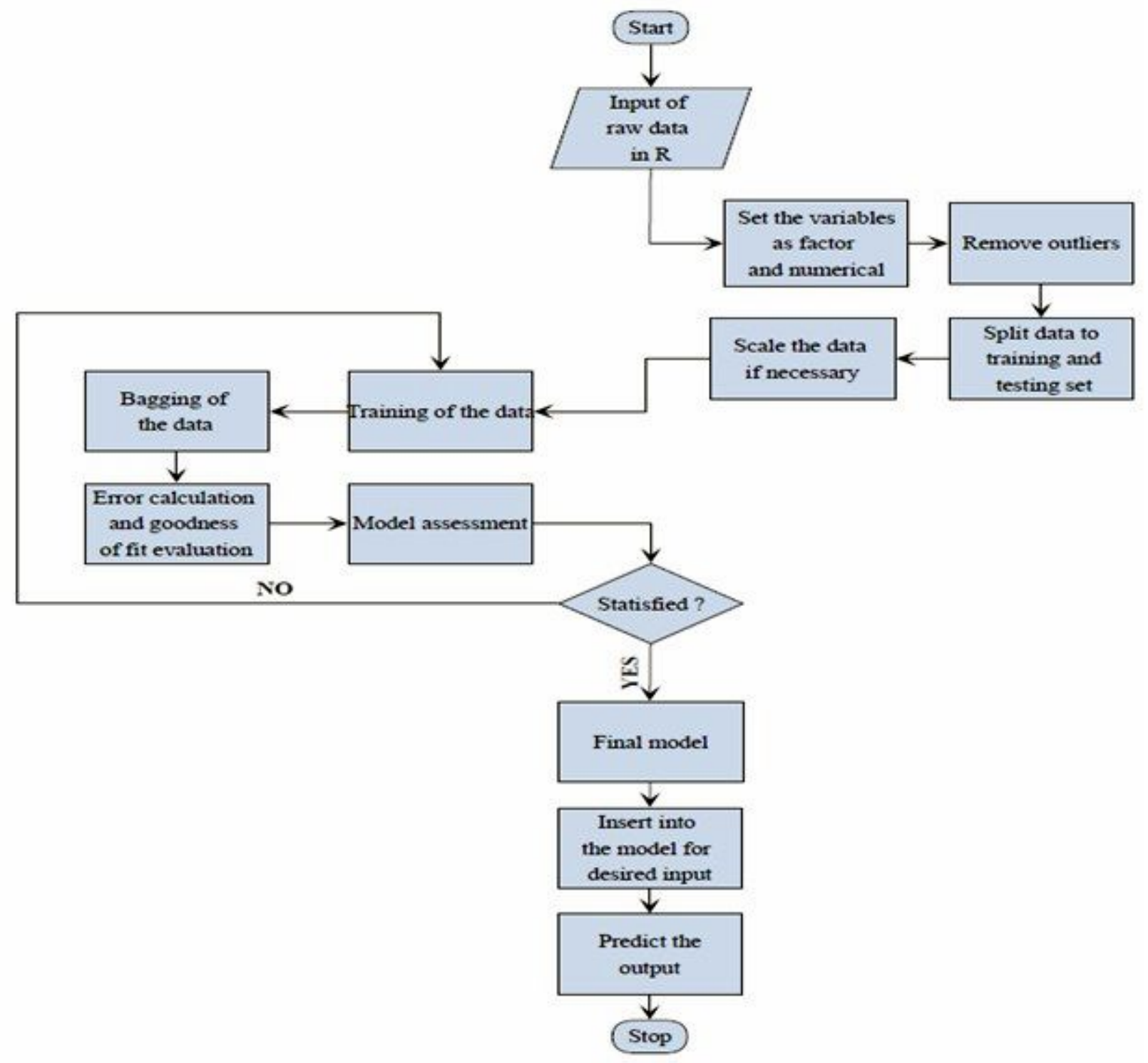

Figure 2

Flowchart of the operation of the random forest regression 


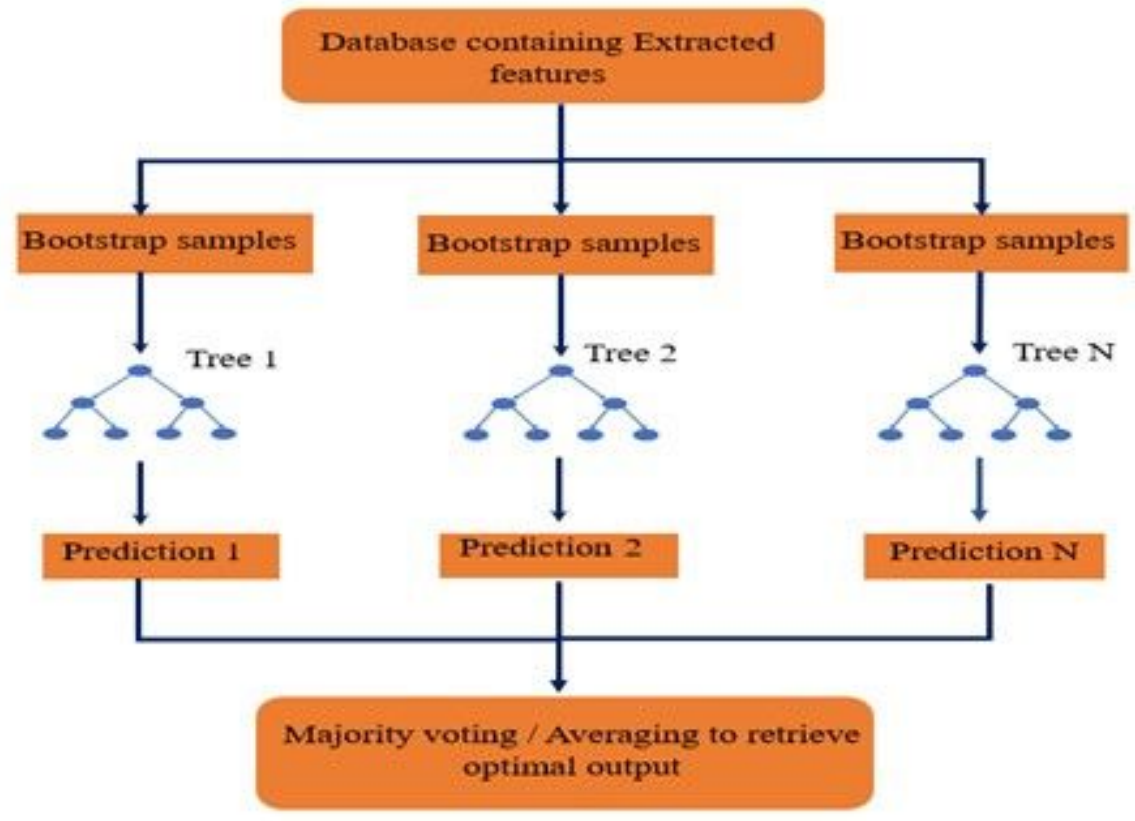

Figure 3

Schematic representation of the random forest regression procedures. 


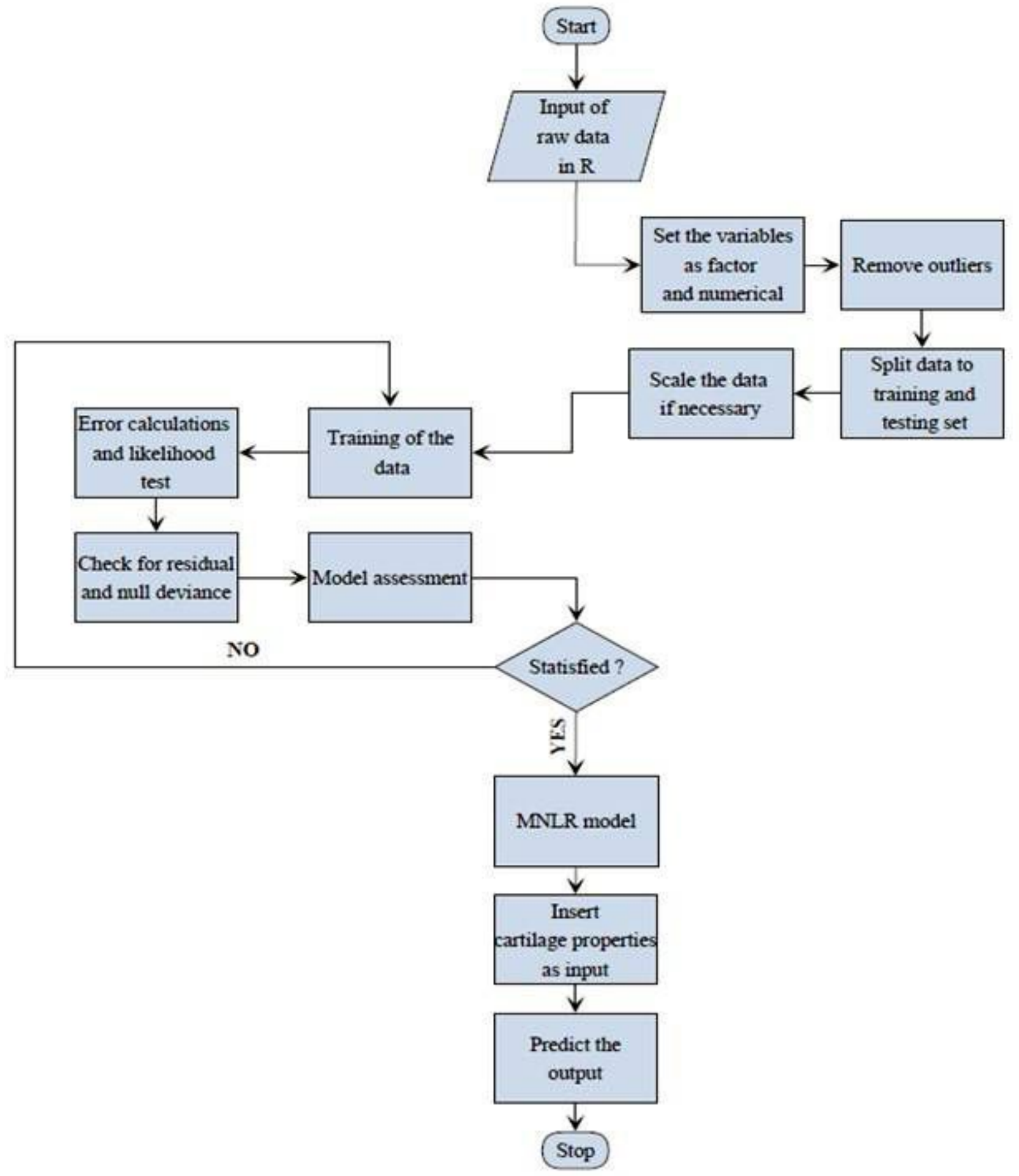

Figure 4

Flowchart of the operation of the multinomial logistic regression. 


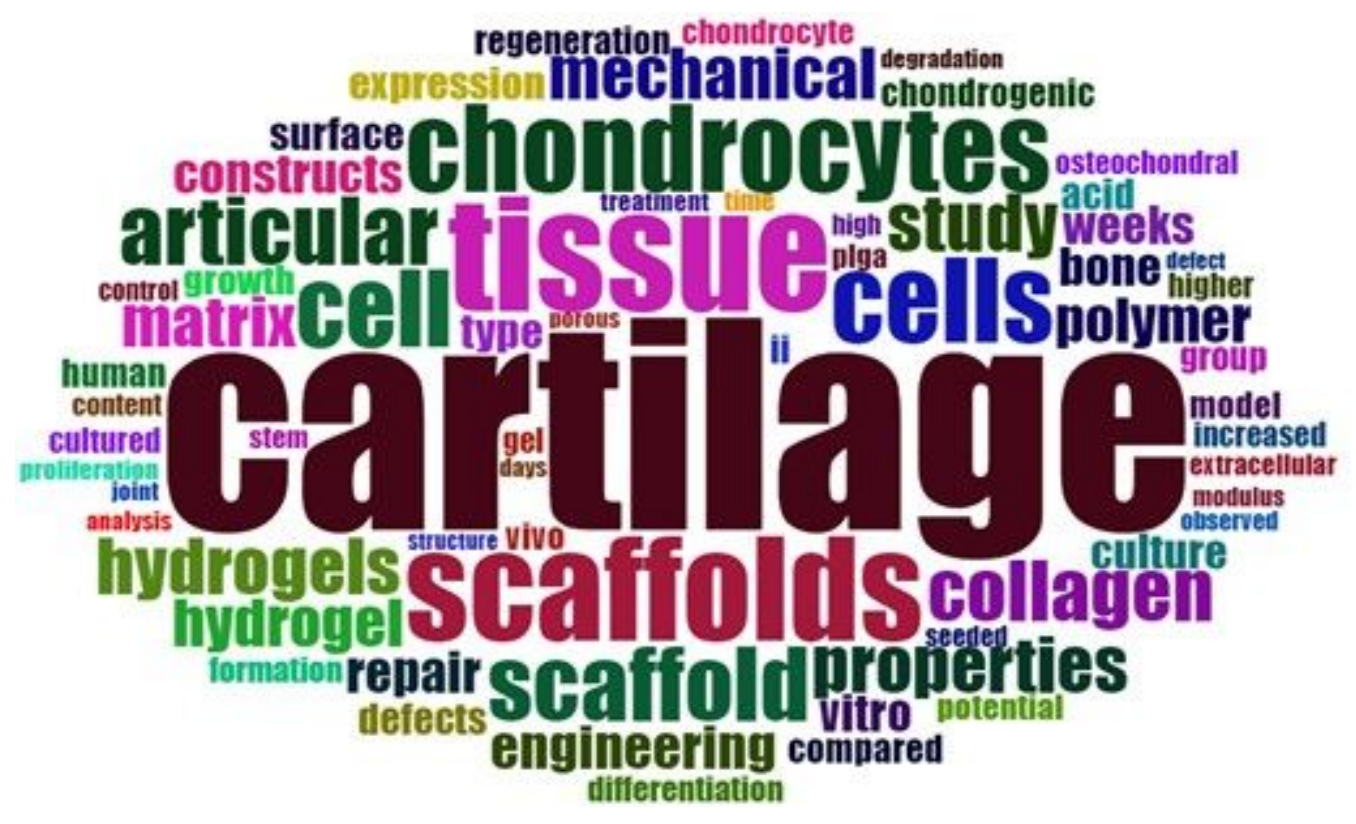

Figure 5

Wordcloud of the most recurrently (> 70 times) occurred words found in the articles' abstracts using 'polymers' and 'cartilages' as the keywords.

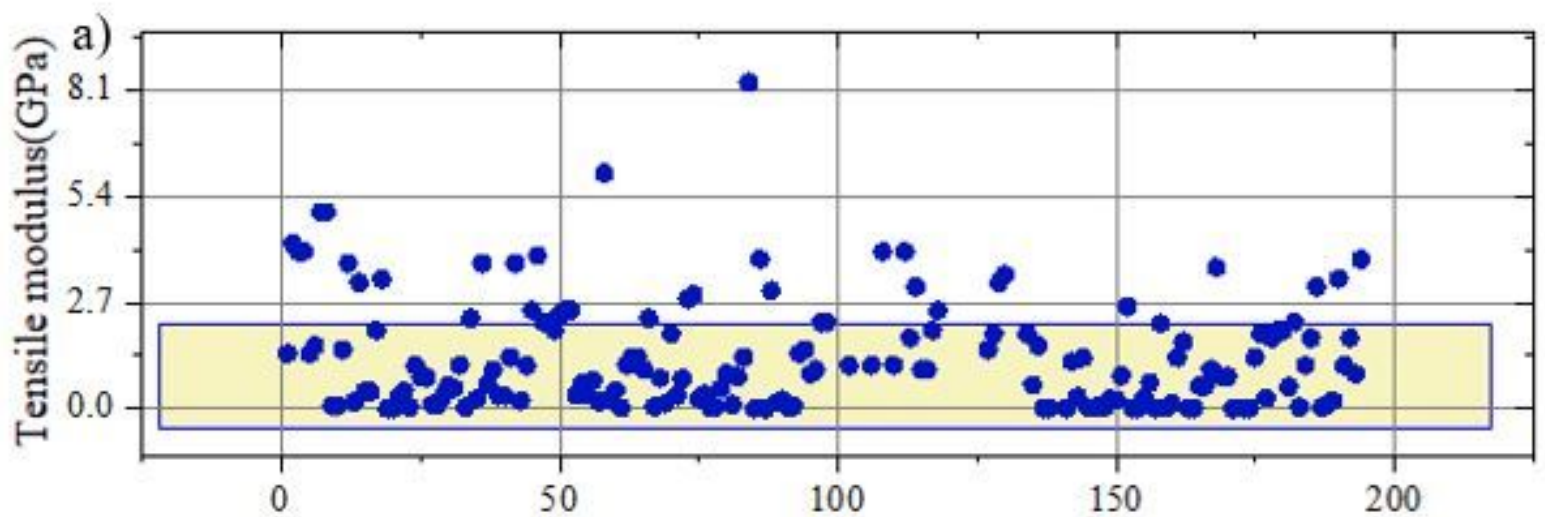

b) Number of polymer

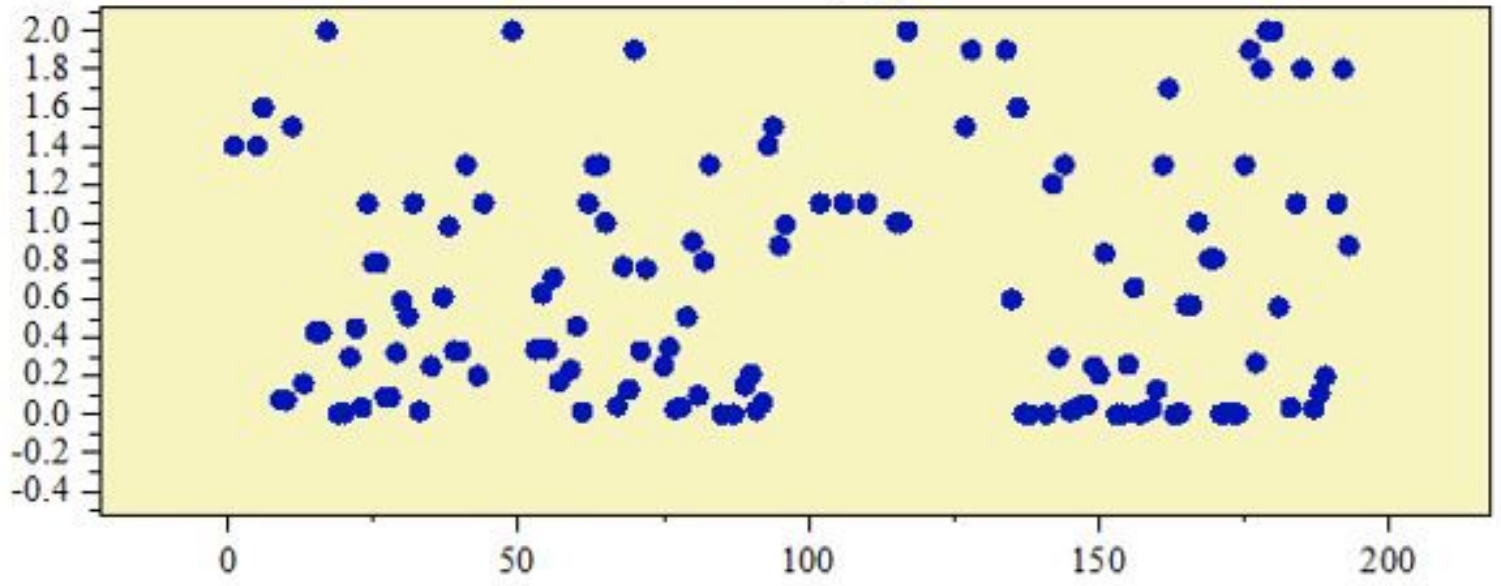

Figure 6 
Scatter plot: a) Overall data of tensile modulus of the polymer(s)/polymer composites in the database; b) Zoomed image of the highly-dense region of the overall data.

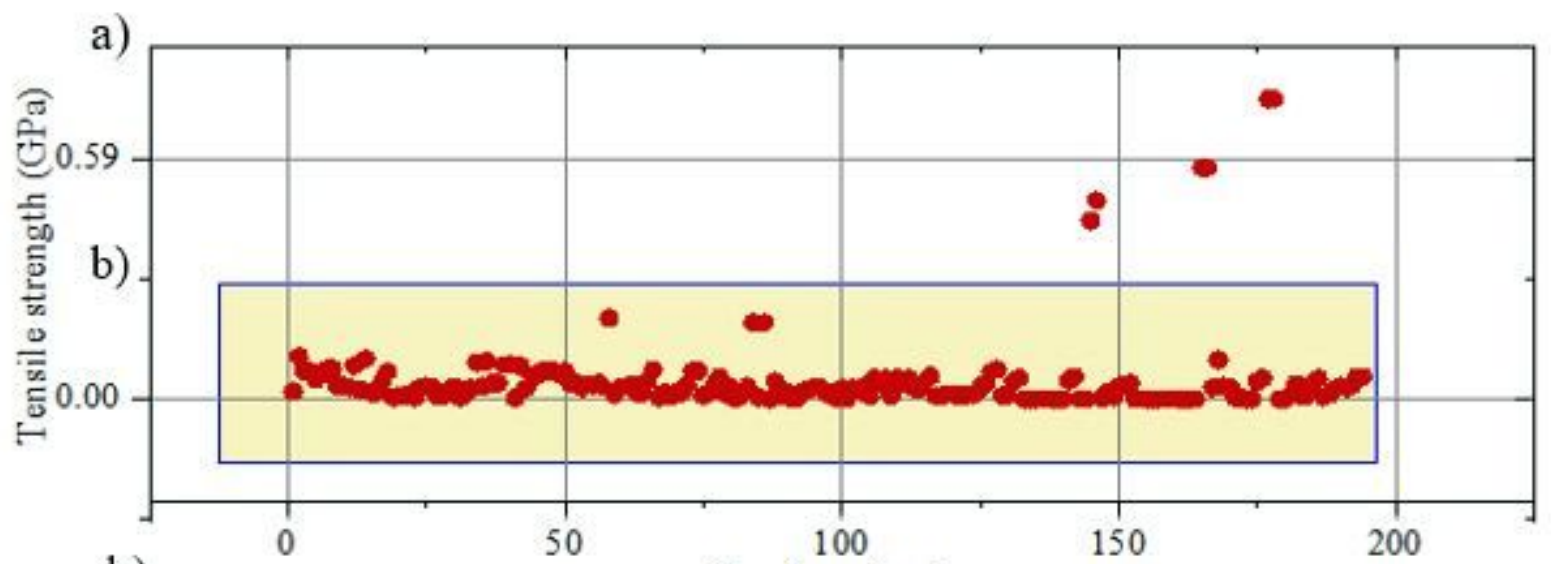

b)

Number of polymers

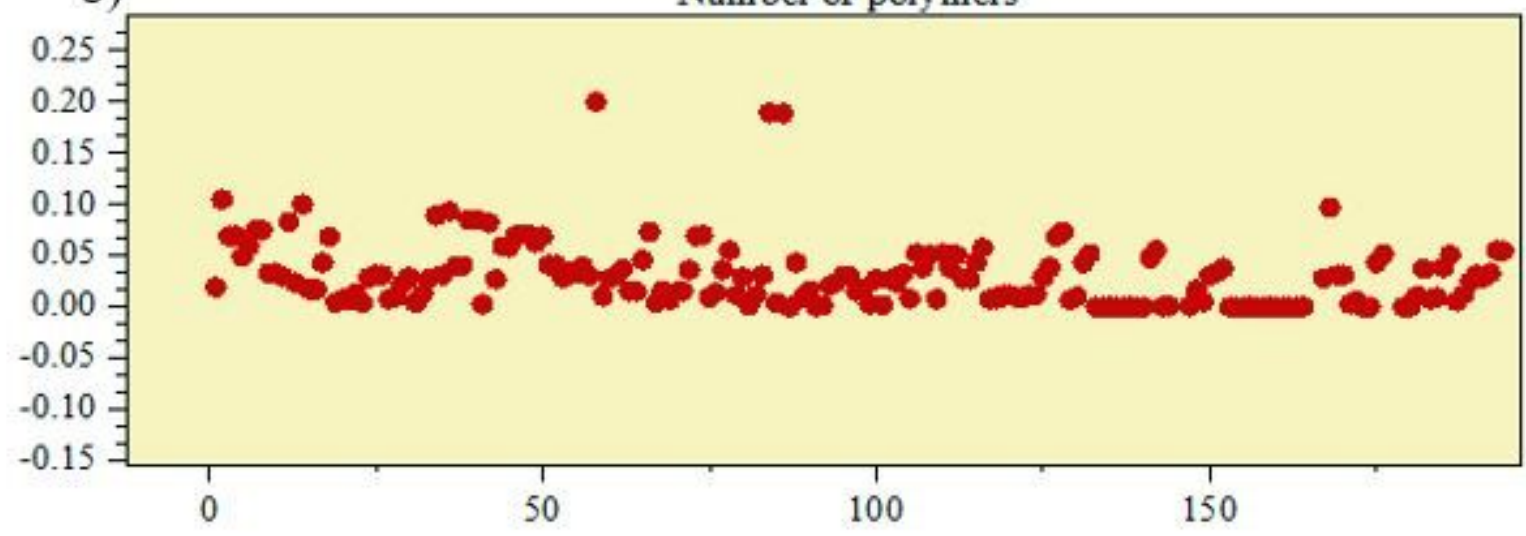

\section{Figure 7}

Scatter plot: a) Overall data of tensile strength of the polymer(s)/composites in the database; b) Zoomed image of the highly-dense region of the overall data. 

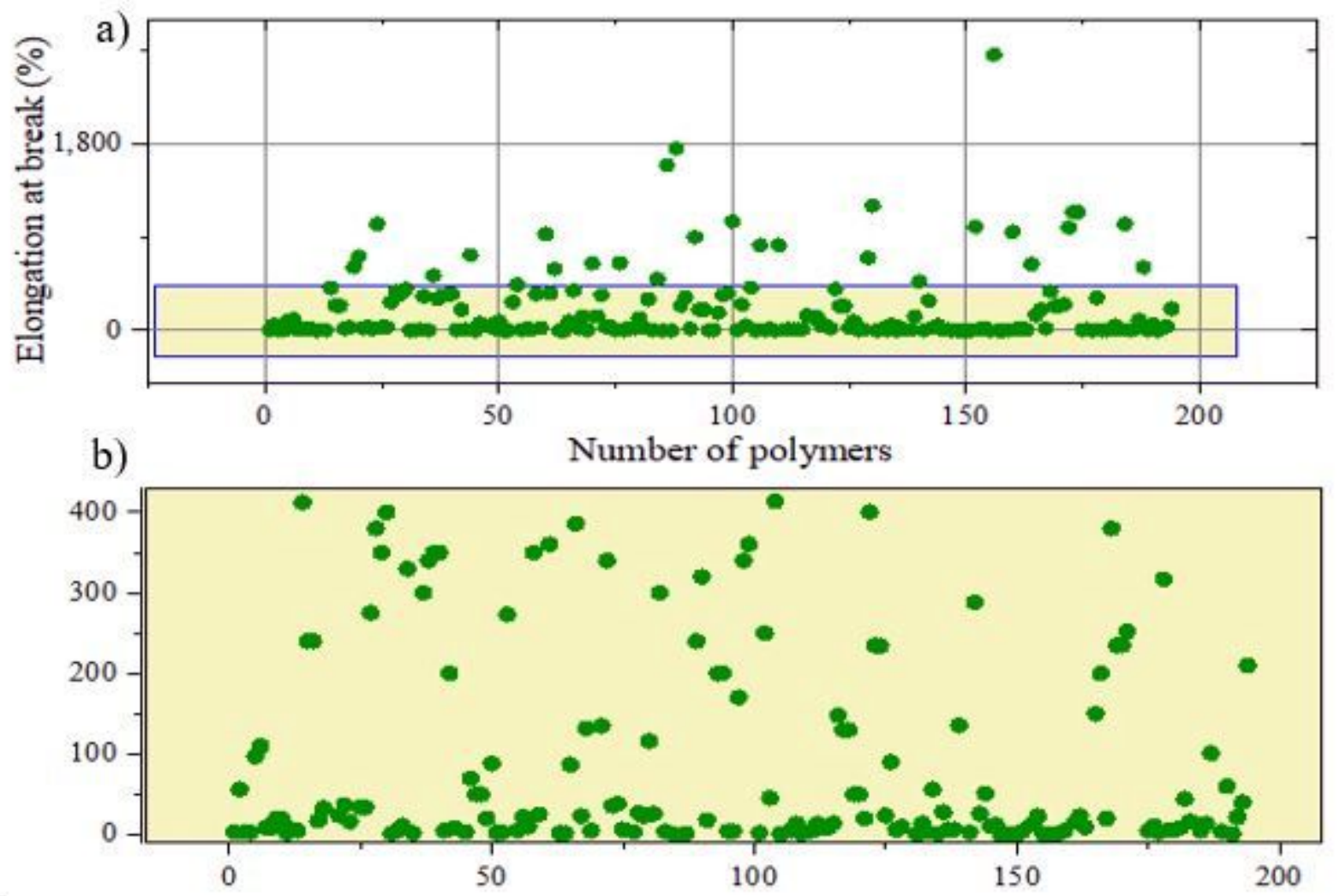

\section{Figure 8}

Scatter plot: a) Overall data of elongation at break (\%) of the polymer(s)/composites in the database; b) Zoomed image of the highly-dense region of the overall data. 

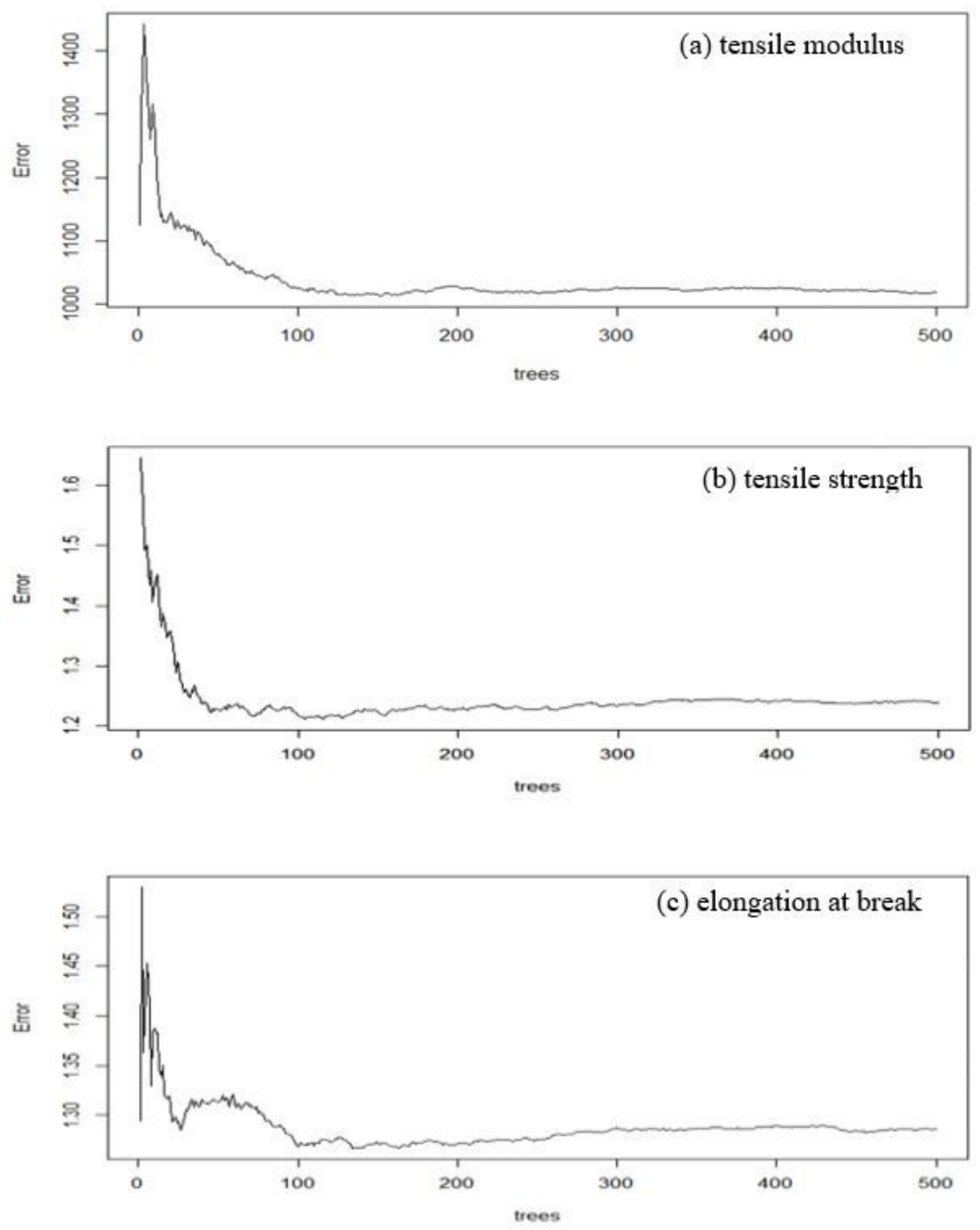

\section{Figure 9}

Error plots: (a) tensile modulus, (b) tensile strength, and (c) elongation at break for the random forest regression modeled data. 

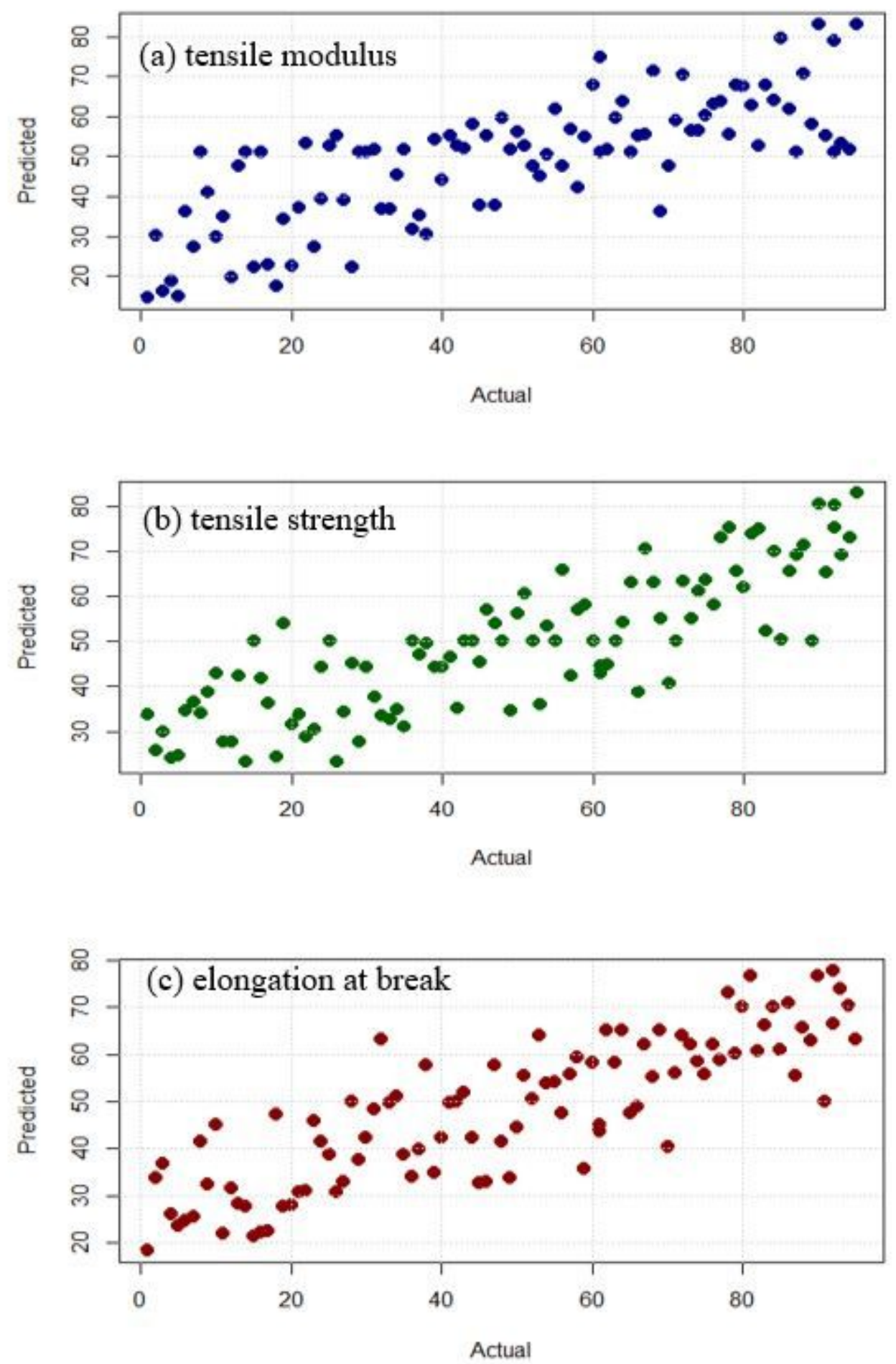

Figure 10

Predicted versus actual results for the testing data collected from the random forest regression. 


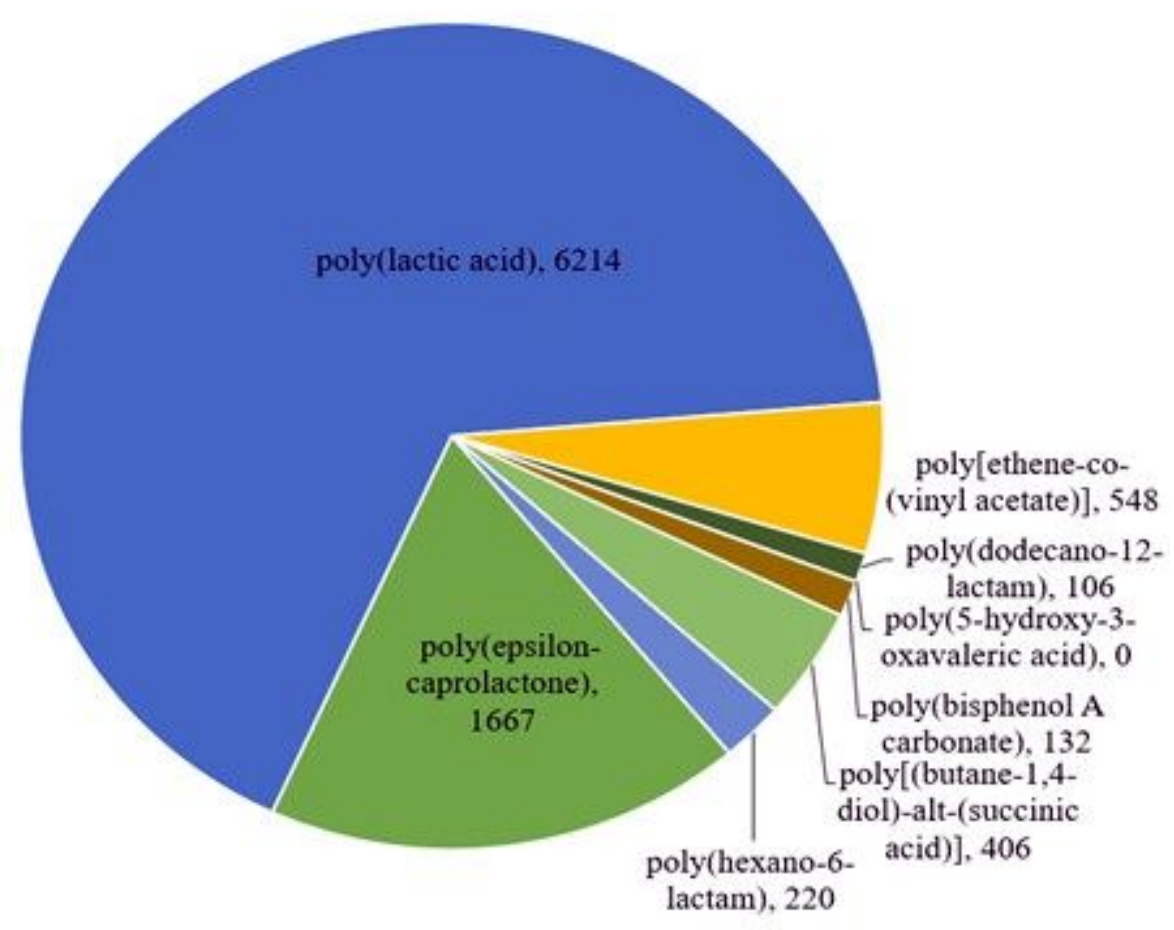

Figure 11

Pie chart displaying the number of times the RF algorithm predicted polymers appeared in the science direct and PubMed journals.

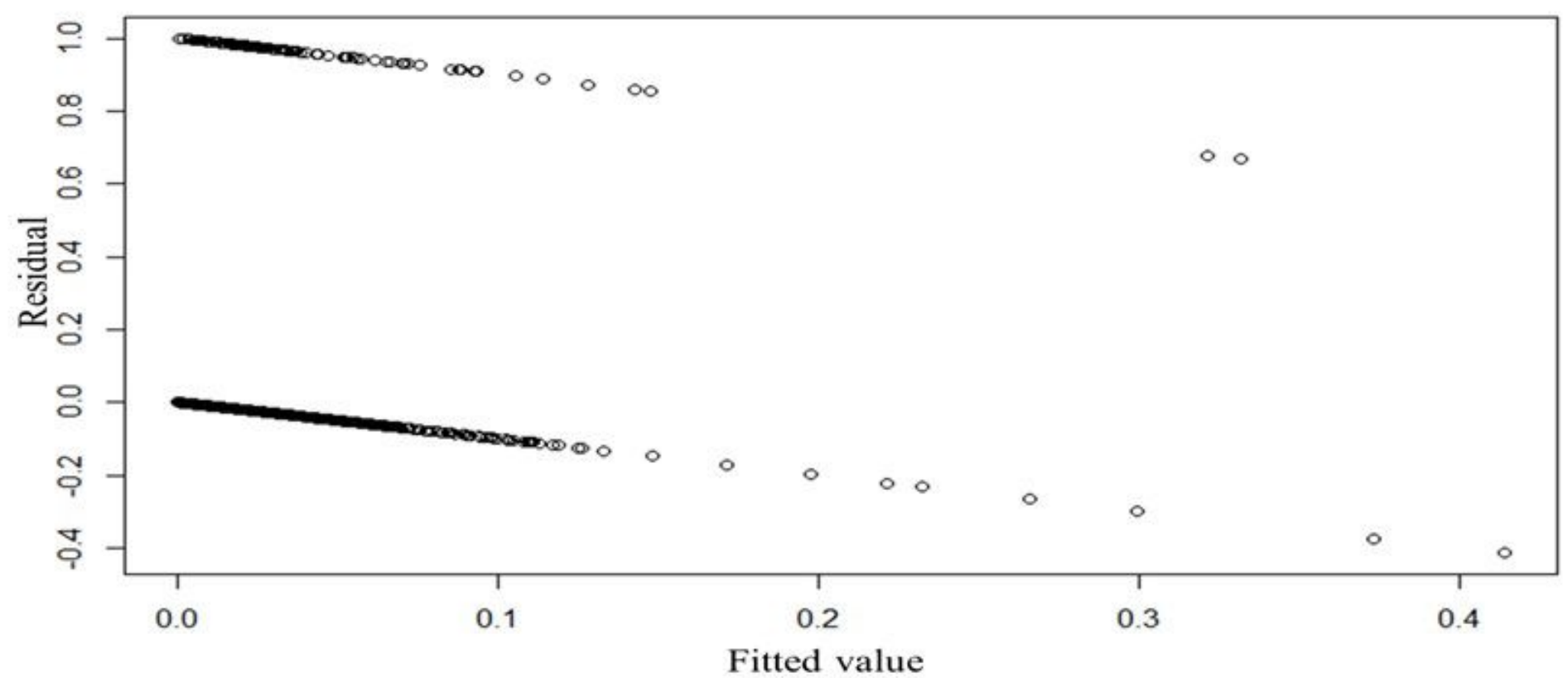

Figure 12

Scatter plot of the residual verse fitted value. 


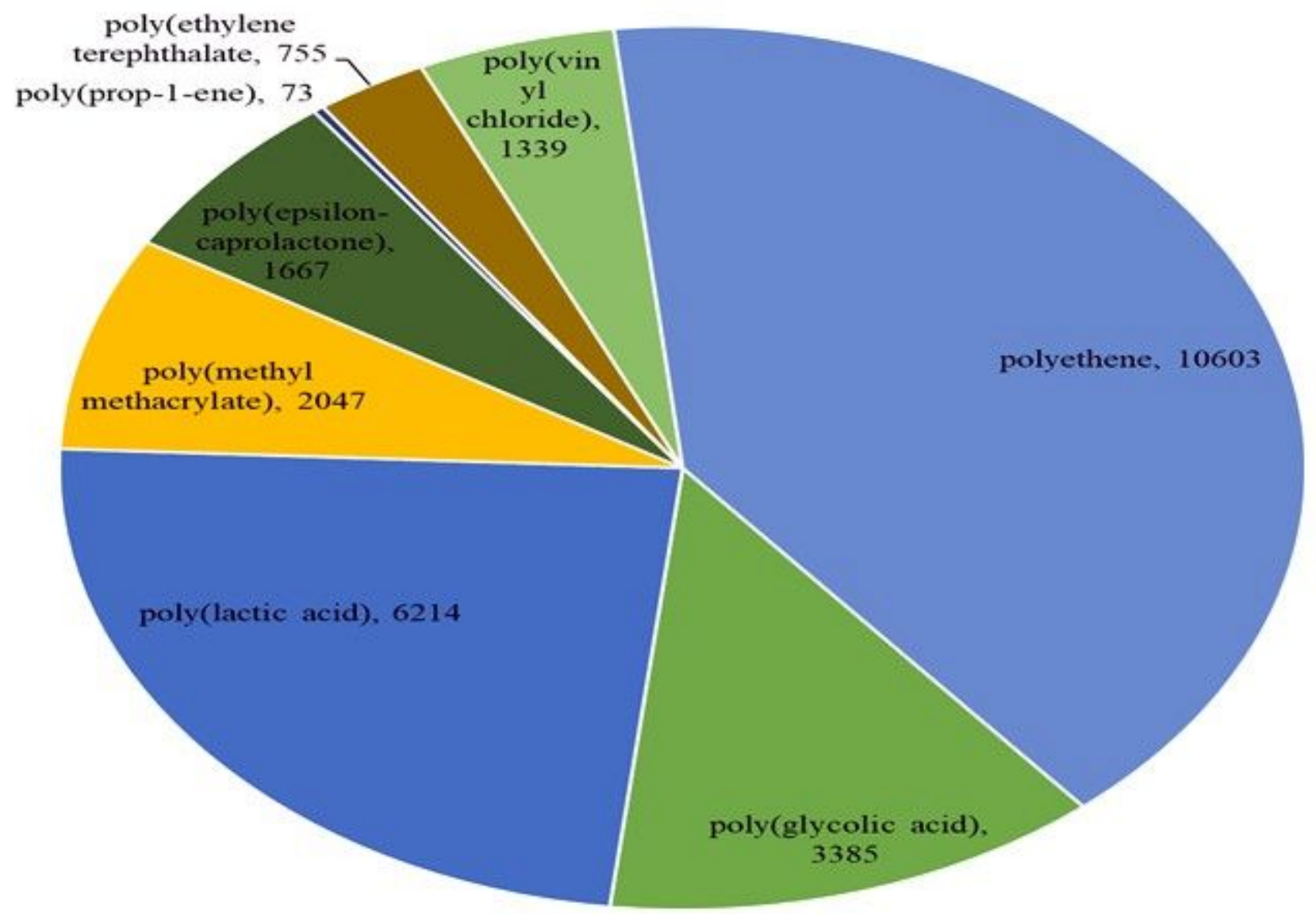

Figure 13

Pie chart displaying the number of times the MNLR algorithm predicted polymers appeared in the ScienceDirect and PubMed journals.

\section{Supplementary Files}

This is a list of supplementary files associated with this preprint. Click to download.

- gaphicalabstract.jpg 